\title{
2 Creative Industries
}

Scholars of regional policies (see Florida, 2002; Florida, 2008; Landry, 2000; Scott, 2006), urban sociology (see Jacobs, 1970; Sennett, 2006; Sennett, 2008; Castells, 2000a; Castells, 2000b; Sassen, 2002; Häußermann, 1987; Häußermann \& Siebel, 2004; Bürkner, 2005) and economic geography (see Lange, 2007; Musterd \& Deurloo, 2006; Musterd et al., 2007) point out that knowledge-intensive services and the socalled 'creative industries' are estimated to be the new urban economy of the knowledge or information society, in other terms also conceptualised as the new accumulation regime structuring our economies (see Brenner, 1998; Marston \& Smith, 2001). US regional economist Richard Florida comments (2002: xiii): 'Human creativity is the ultimate economic resource. The ability to come up with new ideas and better ways of doing things is ultimately what raises productivity and thus living standards.' Ross also observes (2008: 32): 'Creative industries policy is embraced as the anchor of regional development by governments around the world on the lookout for a catch-up industrial plan. In the business world, creativity is viewed as a wonderstuff for transforming workplaces into powerhouses of value, while intellectual property [...] is increasingly regarded as the 'oil of the 21st century'. These two statements indicate that creative industries are thought to be the next growth machine for matured economies in the post-industrial countries. Throughout the first decade of the new millennium there was a strong presence of this topic in the media, policy debates and academic studies. I will use this chapter to clarify what exactly the creative industries sector entails. First, I will contextualise the advent of the creative industries. Then I will present different ways to define these economic activities. Subsequently, I will characterise the creative industries' work conditions and their impact on the lives of creative knowledge workers. Finally, I will also sketch out my own understanding of a creative knowledge worker, and I will derive some conclusions for the empirical interest of this book.

\subsection{The Advent of Creative Industries}

During the 1980s, the UK lived through the Thatcher Era's neoliberal political agenda. As mentioned in the introduction, the post-industrial UK was looking for a future source of income to secure long-term growth. In this process of economic restructuring, the Labour Party (1997) initiated a debate about the role of the 'cultural industries'. When the Labour Party regained political power, it introduced the term 'creative industries' as used by the UK Department of Culture, Media and Sports (DMCS) (cf. Garnham, 2005). Shortly thereafter, the concept of creative industries also became an issue in continental Europe. Additionally, the popularity of the 'creative industries' as a research topic was boosted by US regional economist Richard Florida, whose popular book, The Rise of the Creative Class (2002), found wide reception. 
There are various developments in recent history that have helped the emergence of creative industries and the attention they receive today. Many drivers are mentioned in the literature: reduced working time and the increase in leisure time, improved education, growing real income, a change in consumption patterns, the increasing amount of money spent on cultural services and products, etc. (European Commission, 2010b: 191). Florida integrates the emergence of creative industries into a sequence of historic innovations, following the former periods of the agricultural era, the emergence of mercantilism's trade and specialization, the industrial era, and the organizational age and extension of bureaucracy (Florida, 2002: 45-66). However, I will concentrate on the relation of information and knowledge as well as the role of the Internet and modern information and communication technologies (ICT). I think this context provides a systematic understanding of where the discussion around creative industries comes from.

\subsubsection{The Information Society and the Creative Industries}

Since the 1960s scientific scholars have been studying the transformation of society into something new called 'information society'. The sociologist Jochen Steinbicker provided a comprehensive overview of this topic. In this and the following subchapters, I will mainly refer to his description of the emergence of the information society and the knowledge economy, which he presented in his 2001 book entitled Zur Theorie der Informationsgesellschaft: Ein Vergleich der Ansätze von Peter Drucker, Daniel Bell und Manuel Castells. As the title suggests, he compared three of the main scholars of the information society, Daniel Bell (1976; 1980), Peter Drucker (1969), and Manuel Castells (1997; 2000a; 2000b).

Steinbicker understands Drucker's approach as orientated on a management perspective, as is common in economics. Drucker aims at providing management professionals with a manual for dealing with the growing importance of information and knowledge for economic production. Steinbicker here refers to Drucker's 1969 book 'The Age of Discontinuities'. In this book, Drucker's central argument is that knowledge is the main resource for the economy in the information society. Steinbicker critically remarks that this macro-level economic approach neglects the micro-level perspective of individual people. Individual concepts and notions are important for a sociological study of the information society, Steinbicker claims. Therefore he criticises Drucker's work for remaining incomplete as it is an economic approach too focused on knowledge as a resource for the economy.

Yet, Steinbicker remarks that there are also important elements in Drucker's work, which could help to develop a theory of information society. First, there is the idea that an expansion of education within the society causes structural change. Then, the boundedness of knowledge in a person's mind is important, as this implies the central role of the knowledge worker. The person then becomes more relevant as 
they apply knowledge to knowledge - the central activity in the knowledge economy. Furthermore, Drucker concluded that the growing importance of knowledge as a resource, ongoing technological innovation, and expanding innovation systems will fundamentally change the education system and scientific research.

Here Steinbicker points out that Drucker also identified a contradiction that is inherent to the knowledge worker and that is typical for the information society. Knowledge workers have the power over the knowledge they have in their brains. Thus, they start to feel independent and self-defining, but still they do not exert power over the productivity of this knowledge. This power remains in the hands of the employing or commissioning organizations. While knowledge workers consider themselves autonomous and intelligent, they still depend - similar to a factory worker in the industrial age - on their company (cf. Steinbicker, 2001: 21-48 \& 109-111).

Steinbicker then turns to Bell's approach (Bell, 1976; Bell, 1980), which he considers a more analytical and a more sociological approach than Drucker's. As Steinbicker mentions, Bell's central texts concerning the information society are The Coming of Post-Industrial Society. A Venture in Social Forecasting, from 1976, and The Social Framework of the Information Society published in 1980. Two central axioms characterise Bell's thoughts: first, the central position of codified theoretical knowledge, and second, the shift from the industrial production of goods to service sector dominance. Bell emphasised the centrality of the bureaucratization of science in the information society. This bureaucratization causes the opposition of the professional ethos of scientists against bureaucracy. His notion of a 'third infrastructure', which actually refers to the ICT, is also helpful, as Steinbicker remarks. However, Steinbicker remains critical as he sees many of Bell's ideas falsified through actual developments in time. For example, Bell's idea of a changing character of work towards a playful communication between human beings has not come true. A large share of knowledge work is still based on interaction with computers and machines. Also his idea of a communal society, in which social equality would rise again, has not yet become reality (cf. Steinbicker, 2001: 49-77 \& 111-113).

According to Steinbicker, Castells' approach consists of an empirical diagnosis of various developments in current society. Castells merges his observations into a draft theory of the information society that is based on networks. Here Steinbicker refers to Castells' trilogy, The Information Age: Economy, Society and Culture which was first published from 1996 to 1998 (here I refer to the later editions from 1997; 2000a; 2000b). Steinbicker observes that Castells, as opposed to Bell, better achieves an integration of social change mechanisms in his conception of the information society. He explains social change with the interaction of productive factors (such as knowledge in the form of knowledge workers) with the production system. According to Castells, two developments are at the centre of the advent of the information society. First, networks become the dominant form of organization. Technological and social networks interact and host the main part of communication and information flows. Thus, a culture of 'real virtuality' will make participation in the technology-based virtual 
'spaces of flows' necessary for being part of the society. Second, the role of identification and identity becomes more important. In particular for the individual, selfpositioning in relation to predominant networks is important for finding one's own place in society. In parallel, there is also the emergence of new social movements, which oppose themselves to the networks and their oppression. For Castells, this last point represents a new form of social emancipation. In addition, he witnesses a solution of traditional class struggle. Knowledge workers increasingly are paid in shares and options of the companies they work for. This means they become co-owners of their own production system. Critically, Steinbicker remarks that Castells' blueprint of an information society cannot claim to be a social theory. It neither provides useful analytical tools nor does it explicitly explain the role of technology. Steinbicker concludes that many concepts of Castells' remain unclear and ambiguous (Steinbicker, 2001: 79-108 \& 113-115).

According to Steinbicker, these three authors have delineated helpful contours of current societal developments, but discussions concerning the notion of the information society remain unsatisfactory for those who are looking for a new and comprehensive social theory. Steinbicker looks for similarities in the three authors' literature on which such a theory of the information society might be grounded. He identifies seven comparable characteristics of the information society that can be found in the three authors' approaches (Steinbicker, 2001: 109-124).

First, the information society is based on a new economic system in which knowledge and innovation become the main drivers of economic wealth - as opposed to labour, money, land, or machinery in the agrarian or industrial societies. This includes a change in socio-economic structures. Bell and Drucker supposed that the education sector and scientific research would become the central axes of the information society. Steinbicker, however, is doubtful about that point. Rather, he thinks that education and research will lose autonomy and become more dependent on the financial capital of private companies (Steinbicker, 2001: 115).

Second, the extended availability and capacity of information and communication technology (ICT) is a central asset of the information society. ICT changes the organization of production and consumption. For Castells, ICT plays a major role in the development of the 'space of flows' and a 'real virtuality'. Furthermore, ICT exhibits a strong influence on new ways of communication, defining the character of so-called 'network companies'. They also cause an informational paradigm in the field of knowledge work. For Bell, ICT is the reason for the emergence of 'intellectual technology'. Drucker argues that ICT helps a restructuring of social and economic organization. As Steinbicker puts it, all approaches share the vision of ICT-based economic and social activity as a central aspect of the information society (Steinbicker, 2001: 116).

Third, there is a pronounced change in social organization itself. Vertically integrated and hierarchically organised structures have become less important, and social interaction is increasingly organised in horizontal and flexible ways. Drucker and Castells explain this change independently of the ongoing digitalization and the 
extended use of ICT. For them, organizational change occurs because of the necessity for flexibility, adaptive capacity (life-long learning) and efficiency. Castells mentions that the network organization, which could be understood as an output of this process of change, will be the dominant type of organization. Drucker speaks of creative and knowledge-based organizations. Somewhat opposed, Bell designs his proposal around the observation that cultural change precedes organizational change. The changing cultural norms and values put pressure on hierarchical companies and organizations to develop a more social character and to put less emphasis on economic aspects. Bell stresses the central and axial position of publicly financed scientific research and theoretical knowledge for the economy (Steinbicker, 2001: 116f.).

Fourth, knowledge becomes the central input in the working world. Thus, knowledge workers are strategically the most important group of workers today, and their share in total employment is rising. Again Bell argues differently from Drucker and Castells. For Bell, the central shift in the working world is from secondary sector production (industrial goods and manufacturing) to tertiary production (services). Drucker and Castells rather argue for the changing nature of work itself, irrespective of the economic sector. For Drucker, work is more and more defined by the application and creation of knowledge. This means that formal education is important, less for its content, but rather for teaching people techniques for continuously acquiring new knowledge. This capability for life-long learning is the central resource for knowledge workers. Drucker argues that change in the working world is caused by the expansion of a positive evaluation of formal education in the post-industrial societies. Thus, it is first of all a cultural change concerning norms and values that includes a higher evaluation of education. This shift in values and norms is in line with Bell's argument that the information society comes along with rising importance of postmaterialistic values, such as liberalism, a focus on educational attainment, health, quality of life, culture, etc. Like Drucker, Castells stresses the role of 'adaptive capacity' in informational work environments. However, Castells does not speak of a wider shift in value systems. According to him, only the culture of a 'real virtuality' and the ensuing bottom-up social movements are an indication of cultural change. Steinbicker summarises that the three approaches share the conviction that the growing role of knowledge, technological necessities and communication will alter the formerly hierarchical modes of control and organization in the working world (2001: 117f.).

Fifth, there is a transformation in the factors that define social stratification. Increasingly, access to knowledge and education is a central element for a person's position in society. While Bell and Castells speak of talent and skills as the central criteria for being in an advantaged position, Drucker argues that, even independent of talent and skills, everyone has the possibility to become a successful knowledge worker through education. The growing importance of the educational system is central in all these approaches. This includes the awareness that a person's social position will most likely be defined by access to and the use of the educational system (Steinbicker, 2001: 118f.). 
Sixth, the state loses power in regulating the social system. The power relations between the economy and the (nation) state change in favor of the global economy. Here, the three authors show significant differences in their interpretations, as Steinbicker remarks. Drucker expects the formerly central position of the state to be devalued through the rise of competing organizations (e.g. NGOs, multinational corporations). The role of the state will be reduced to a coordinating function. For Bell, the political elite will remain central and will develop new modes of control that will be diversified internally through particularistic lobby groups. In contrast, Castells thinks that societal organization will be based on networks, which themselves will exhibit power within distinct social spheres. A new 'networking logic' will develop and will determine society. Important networks such as the global financial system, the global media, the networks of political institutions, and multinational corporations will all form 'spaces of flows' around the globe, in which communication and information flow are based on ICT (Steinbicker, 2001: 119).

Seventh, new social conflicts will arise. There will be less of an industrial conflict between labour and capital. Yet, given the growing divide between high-skilled knowledge workers and non-skilled/low-skilled service workers, emerging tensions are expected in the field of service industries (Steinbicker, 2001: 9-11). Bell mentions that a conflict between meritocracy and populism might evolve. Bell and Drucker also envision a conflict between knowledge workers, with their individualistic ethos, and the ongoing bureaucratization of the knowledge economy, in particular in the field of scientific research.

Steinbicker concludes his comparison of these three approaches with the observation that they still do not form a coherent theory of the information society. According to him, merging the three approaches is not possible, as individual concepts within them even argue in opposite directions. Yet, two main aspects are similar. First, productive factors change. Knowledge becomes the central resource for production. The relationship between science, the state and the economy will change. The economy will be differently organised than in the industrial production. Second, the working world will change dramatically. Knowledge workers will be confronted with inner conflicts between their self-understanding (emphasizing autonomy and selfactualization) and their role in the economic system (functioning element in bureaucratic companies). Even though he criticised Bell's idea of a more humane character of knowledge work, Steinbicker still believes that work will be more playful in the future. This is because it will be happening more between people. In the industrial society, work was often an interaction between human beings and large machines. In the information society, it has become more communicative and interactive through human-human relations, even if mediated by ICT. These two aspects might form a frame for a theory of the information society, which would still need further empirical elaboration (Steinbicker, 2010: 121).

It becomes clear in this brief documentation of the discussion around the notion of the information society that this concept is clearly linked to the central role of infor- 
mation, knowledge and innovation. Dealing with and developing new knowledge, trading information and processing information are all activities that have become more and more important in the post-industrial society. The main supporters of this change are the knowledge workers.

How is this discussion on the information society linked to the notion of the creative industries? Looking at recent policy documents, creative industries and creative knowledge workers are now described as fulfilling a bridging function between arts, philosophy, science and business (cf. European Commission, 2010c: 5). They are linked to the extension of the information society (European Commission, 2010c: 2). We can see that creative industries and creative knowledge workers are understood as a central group of actors in the information society who put into practice the first of the seven elements that Steinbicker outlined in his reflection (see above): creative knowledge workers assist in linking the innovation and creation systems closer to the economy and to the private capital. In addition to being a pioneer group, producing innovation and information, they are a driving element in the emergence of what is called information society.

Creative knowledge workers could therefore be considered a specific group of workers who are part of the advantaged group of high-skilled knowledge workers. In the literature stemming from scholars of the information society, on the one hand, and from scholars of the creative industries, on the other hand, we can find many similarities in the description of these workers. Here, one can understand the information society as one of the sociological anchor points of the creative industries. The study of creative industries is often conducted by regional economists and economic geographers who take an economic perspective. They look primarily for the impact of creative industries on regional development, using a focus on economic and financial aspects (e.g. growth rates, employment, productivity and turnover). However, concerning the social character of creative industries, much has already been announced in the early work on the information society (e.g. the growing role of knowledge, information, communication; the centrality of ICT; the network based organization; postmaterialistic values). It is very helpful to look at these sociological results in the field of 'information society' studies in order to better understand what creative industries are like.

\subsubsection{The Knowledge Economy and the Creative Industries}

Apart from wider societal shifts to an information society, there is also literature which deals with a stronger focus on the changes taking place in the economic system. Steinbicker's 2001 textbook is also helpful for recapitulating the emergence of the knowledge economy as a scientific topic. He describes how economists began to deal early on with the role of data processing and information for late-industrial production. The economist Fritz Machlup (1962) was the first to speak about the 'knowledge 
industries'. Machlup's study The Production and Distribution of Knowledge in the United States, from 1962, is considered the groundbreaking work for the development of studies around the 'knowledge economy' (cf. Steinbicker, 2001). Machlup tried to quantify how much of the US gross domestic product (GDP) was based on knowledge work. His basic distinction was that of 'knowledge producing activities' and 'nonknowledge producing activities'. Machlup identified a 29\% share of GDP related to the knowledge economy for the US in 1958. He also observed an increase from $11 \%$ of knowledge work in 1900 to 32\% in 1959 (referring to knowledge producing activities according to his definition).

While Machlup also included the domestic and private work (e.g. of parents who teach their children) or on-the-job training, Porat excluded such non-market activities in his studies in the 1970s. Based on Machlup's ideas, Porat divided the economy into four sectors: extraction (agriculture, mining and resources), producing industries, service activities and information services (cf. Steinbicker, 2001: 15-17). Porat and Rubin then introduced the important novelty (Porat \& Rubin, 1977) of distinguishing between a first and a second information sector. The first information sector consists of companies which primarily produce, sell or trade with information. The second information sector contains the organizational entities of large industrial corporations which process information as a service to other industrial activities within the same organization (e.g. the advertisement department of a car manufacturer). Porat reports a $46 \%$ share of GDP for the US in 1967, being spread to $25 \%$ in the first information sector and to $21 \%$ in the second information sector. Both authors, Machlup as well as Porat, predicted an extensive growth in the knowledge economy, but which actually did not happen as quickly as expected (cf. Steinbicker, 2001:16f.).

With the advent of information's mass distribution through radio and TV, Japanese authors also started to deal with the knowledge economy (cf. Morris-Suzuki, 1988). In 1963, Japanese author Tadao Umesao also developed a four-sector model of the economy, including a distinct information sector (cf. Steinbicker, 2001: 17f.). Umesao was convinced that the mind would become industrialised and the future society's main activity would consist in the production of symbolic value. In the 1960s, the Japanese government also commissioned several studies that dealt with the advent of the information society. As Steinbicker mentions, the notion of the 'information society' itself dates back to Yujiro, who suggested that the growing wealth in advanced industrial economies would lead to an increased demand in emotional goods orientated to fashion, lifestyle and quality. According to Yujiro, this was related to a growing share of information costs in the total production costs of many goods (e.g. costs for research and development, design, marketing) (cf. Steinbicker, 2001: 17f.). Thus the Japanese authors observed the link between societal and economic changes early on.

Given the rise of the knowledge economy as the wealth generator of the information society, we should also consider the relationship of the knowledge economy to creative industries. First, empirical data suggest that creative industries are an important part of the wider knowledge economy. Labour Force Survey data indicates that 
creative industries have the highest proportion of employees with tertiary education (ISCED levels 5 \& 6), ranging up to $57 \%$ as compared to $26 \%$ in the total EU economy (European Commission, 2010b: 199). Changing the perspective from employmentbased to occupation-based numbers, the share of tertiary education increases to $78 \%$ in creative occupations as compared to $24 \%$ in non-creative occupations (European Commission, 2010b: 202f.). I would interpret these numbers as primary evidence for the close interrelation between the creative industries and the education sector. Creative knowledge workers consume knowledge and information before entering and while working in the creative industries. This knowledge is, in fact, sold by the educational institutions, which are a central element, as they trade knowledge within the knowledge economy. By contrast, the highly-skilled creative knowledge workers also 'create' and produce new knowledge, which is sold to the educational sector. Both sectors are strongly interwoven and interdependent. Creative industries produce knowledge, symbolic value and emotional goods, which are often distributed to the wider economy and society through the educational sector.

Another point is the high share of labour costs in total value added in the creative industries. Creative businesses' main production asset is their human capital, the creative worker who is used to provide a service or good. Thus, staff costs range the highest on the input side. In other words, labour productivity is generally higher than in the total economy. This again indicates the central role of the creative industries as a part of the knowledge economy (cf. European Commission, 2010b; European Commission, 2010c).

UK data also show that creative businesses are more innovative than other economic sectors. This refers to different aspects of innovation concerning products, processes and broader general innovation. While 32\% of the UK's creative businesses have introduced new products in the last three years, only $21 \%$ of other economic sectors equally did. In addition, $16 \%$ of creative businesses improved their production processes, as compared to $11 \%$ of all other businesses. This difference becomes even more pronounced when distinguishing between the more relevant new-to-market innovation and the less relevant new-to-firm innovation. Additionally, wider innovations were presented by $40 \%$ of creative businesses and only $29 \%$ of all other businesses. The Community Innovation Survey (CIS) data suggests that the main drivers of this innovation are the software businesses within the creative industries. They have a high output of innovative software products and licences, but advertising and architecture are also drivers of innovation through continuously creating new service models. Reporting this data, the European Commission conludes that creative industries 'engage in more innovation-related activities, undertake more $R \& D$, invest more in training, and spend more on design than firms in other sectors' (European Commission, 2010b: 218ff.). Evidence can also be found for the strong linkages between universities/ scientific research and the creative industries, with creative industries evaluating fundamental research more as important than many non-creative businesses. Finally, customers and clients are also considered an important source of knowledge to be used 
for innovation and for breaking up traditional hierarchies between experts and nonexperts. In particular, software and architecture firms tend to use these two sources of knowledge and innovation in an extensive way (European Commission, 2010b: 221).

We can see that creative industries are prototypical for the character that is attributed to the knowledge economy. They are dominated by service sector activities that require high-skilled labour. And they are based on the elaboration of knowledge through creative processes. Furthermore, they often produce symbolic content, which serves as an intermediate input to industrial companies which later sell physical goods.

\subsubsection{Internet, ICT and the Creative Industries}

According to Steinbicker (2001), early scholars in the 1950s tended to think of the extension of automation as well as information and communication technology (ICT) as a deliverance from the social oppression through labour. The future vision entailed a large share of people working in the service sector, in which automation and rationalization seemed impossible. On the other hand, there was an infinite variety of new and innovative services that might be invented and transformed into tradable goods. The emergence of a more leisure-based society was also observed in that time. Steinbicker (2001: 13-15) critically examines the supposed link between ICT and the emergence of the information society. The rapid integration of the notion of 'information society' into political and scientific debates was not caused by but accompanied the rapid extension of ICT availability, as he says. Steinbicker mentions that there were already discussions about information society - e.g. in the 1960s with early microelectronics as well as mass TV and radio access - before ICT even became available for the wider public throughout the late 1970s. In fact, the ICT development path could be traced back to the early 19th century, when no one imagined an 'information society'. Steinbicker argues that there is only a temporal coincidence of the ICT's and the information society's advent. Yet, there is no unidirectional causal relation between the two. The link between the two is always dependent on social structures and their capacity to include ICT in societal organization, as Steinbicker remarks.

Though we do not live in a world in which we are released from work, as envisioned in the 1950s, I posit that the development of ICT was a milestone for the advent of creative industries. While the technological development and the affordability of ICT itself enhanced the efficiency of the creative production process (cf. Sinan et al., 2012), so could new business models be developed only through the emergence of the Internet. Today a large number of successful creative businesses are based on internet-mediated access to clients and customers.

We can find some arguments for this in the European Competitiveness Report, published by the European Commission (2010b). The Internet has been important for the creative industries in several ways. First, the development of the technology itself including software development - and the extended provision of ICT infrastructu- 
res allowed for an easily accessible virtual marketplace. Therefore, the Internet is an important issue on the sales side, namely for the distribution of creative goods and services. In the European Competitiveness Report, the European Commission mentions: 'ICT and the internet are leading to new forms of distribution, more choices for consumers, and a more efficient production process' (European Commission, 2010b: 191). New business models are evolving in the field of e-commerce. For instance, the advertising sector has gone through a wave of massive digitalization, with online advertising making up at least $20 \%$ of the EU market. The music industry has similarly been affected by the expansion of digital markets, with decreasing sales in traditional retail stores and an increasing, very dynamic online market (European Commission, 2010b: 199). These developments are strongly based on the growing accessibility of clients and customers through the Internet. More people tend to be online, they stay on the Internet for more time, and they have better broadband access. In 2009, a study by the International Federation of Phonographic Industries (IFPI) even reported a correlation (at the level of 0.8 ) between the availability and use of broadband internet connections, on the one hand, and the size of creative industries in different EU regions, on the other hand (IFPI, 2009; cited according to the European Commission, 2010b: 199). Thus, the technological possibilities that come with ICT seem to be exploited in efficient ways by actors in creative industries. The European Commission writes (2010b: 218): 'Current means of mass (re)production, mass consumption, and commercialization of artistic/creative content have been made possible mostly by technological advances in the fields of information and communication technology (Cunningham et al., 2004). In fact, creative industries are intense users of ICT innovations in particular, as well as other new technologies. For instance, digital technologies and compression methods for audio and video signals that allow efficient storage and rapid transmission with little loss of quality have created new, low-cost means of sales distribution.'

Seventeen percent of non-creative businesses operated their own e-commerce solutions by 2000 -in comparison with $30 \%$ of creative businesses. Creative industries have been early adopters of ICT innovations, as W@tch Survey data from 2005 indicates (European Commission, 2010b: 219). Also, in the Green Paper on creative industries, the European Commission stressed the central role of ICT, which provides 'new opportunities for creators to produce and distribute their works to a wider public at a lower cost, independently of physical and geographical constraints.' (European Commission, 2010c: 6).

Recently, the UK-based Interactive Media in Retail Group (IMRG) published its B2C Global e-Commerce Overview 2012 ${ }^{3}$, in which it estimates that the global volume

3 http://imrg.org/ImrgWebsite/User/Pages/B2C_Global_e-Commerce_Overview_2012.aspx (accessed 14 April 2014)

http://www.internetretailer.com/2012/06/14/global-e-commerce-sales-will-top-125-trillion-2013 (accessed 14 April 2014) 
of e-commerce was US\$ 961 billion in 2011, which indicates an increase of $20 \%$ over the previous year. The USA represents the world's largest national market, totaling US\$ 297 billion. Between 2011 and 2012, China had a growth rate in e-commerce of $130 \%$, and the EU represents the largest market worldwide, accounting for a total volume US\$ 307 billion. Furthermore, the study suggests that 2.2 billion people worldwide use the Internet. The number of internet users is rising rapidly and it will reach $50 \%$ of the world's population in the coming years. In 2010, the US Census Bureau published another study ${ }^{4}$, in which the authors calculated estimates for e-commerce volumes based on annual business surveys. Here, it becomes obvious that businessto-consumer (B2C) e-commerce only accounts for $10 \%$ of all US e-commerce. Thus, the business-to-business (B2B) e-commerce volumes are much larger. In the US economy, e-commerce accounts for $16 \%$ of all value of shipments, sales, or revenues. These numbers highlight that there is a growing sales potential in virtual markets for all types of creative businesses.

Second, the Internet has also become a large source for market-relevant information and knowledge. As such, it is a productive factor. In a study done at the University of California Berkley's School of Information Management and Systems in 2003, ${ }^{5}$ it was estimated that each person on the planet produced about 800 Mbytes of new information in that year alone. The annual growth rate of information of mankind was 30\% between 1999 and 2002. Furthermore, the authors found that 750 Gbytes of information circulated through instant messaging each day, equalling 274 Terabytes a year; email accounts totaled 400,000 Terabytes a year; and $92 \%$ of new information is stored digitally. Even though there might be a lot of methodological issues in these figures, they still provide an estimate of the relevance of the Internet as a source of information.

Third, the Internet allows for a flexible organization of work. With internet-based communication tools (virtual hard drives, cloud computing, chat rooms, online telephoning), the production of creative goods and services is increasingly organised without physical co-presence in one place. This does not mean that face-to-face contact becomes unimportant, but teams can be managed in a more flexible and independent manner.

\subsubsection{Information, Knowledge, and Creativity}

At this point it might be helpful to come back to the different semantics of the three words knowledge, information and creativity. They are actually at the core of the

4 http://www.census.gov/econ/estats/2010/2010reportfinal.pdf (accessed 14 April 2014)

5 http://www2.sims.berkeley.edu/research/projects/how-much-info-2003/execsum.htm\#summary (accessed 14 April 2014) 
issues that I have discussed above. So far, I have used these terms in an unreflective way. I have done so for practical reason, namely in order to illustrate how the ideas of a knowledge economy, an information society and creative industries can be linked. Still, I think we must come back to these three basic notions to understand how the focus on creativity and creative production evolved from the other two terms.

Abel (2008) provides a detailed discussion of the notion of 'knowledge'. According to Abel, there are different forms of knowledge which can be differentiated from each other. Generally one could say that knowledge consists of 'everyday habits, customs, competencies, and practices as well as science, technology, and institutions of the modern civilized world' (Abel, 2008: 11). However, this general understanding does not greatly increase our understanding of the character of knowledge. Abel then explicates that there is a narrow and a broad way to speak of knowledge. The narrow way refers to knowledge 'obtained by a methodologically well-regulated procedure bound to justification, truth, and verification' (Abel, 2008: 12). This includes the following criteria: that a person is able to explain how this knowledge came into existence and that the knowledge generation must be intersubjectively verifiable. The broader definition, by contrast, refers to all everyday life knowledge ('know-how') which helps us to orientate in the world and to react appropriately within any given situation. Based on this two-fold differentiation, Abel then introduces a four-fold system of forms of knowledge. First, there is everyday knowledge (the unreflected basis for action); second, there is theoretical knowledge (e.g. mathematics); third, there is knowledge of action (knowing how to do things); and fourth, there is moral or orientational knowledge (guiding social interaction).

In all these four forms of knowledge one can further distinguish between the different ways that these forms of knowledge can be transported intersubjectively. On the one hand, there is explicit knowledge that is displayable, as Abel says. This means that other people can also obtain that knowledge through indirect ways (independent of direct communication with the knowledge producer). Reading a book could be an example of one such transfer of explicit knowledge. By contrast, implicit (or tacit) knowledge is not displayed. It is inherent in a person's mind, and it links different things that we know in any given situation.

Furthermore, knowledge can have a verbal character, which means that it is articulated through language. Conversely, the articulation of non-verbal knowledge is not limited to specific linguistic systems; it can be transported through other channels. Abel also explains that there is a difference between propositional and non-propositional knowledge. Propositional knowledge can be expressed in a 'that clause' through words (knowing that something is). On the other hand, non-propositional knowledge cannot be put into such coherent wording. Finally, there is also a distinction between matters of fact, which consist of existing objects and events, on the one hand, and abilities or skills, on the other. Matters of fact can be observed and perceived by different people. Abilities and skills are bound to a person, and they refer to the 'knowhow' of doing things. 
For Abel, knowledge is not something atemporal or innate that exists independently from a person's individual context. Rather, knowledge is embedded in specific cultural contexts: 'The thesis is that, for humans as finite and perspectivist beings, contents of knowledge and forms of knowledge cannot exist independent of the forms, practices, and dynamics of the underlying representational, interpretational, and sign system' (Abel, 2008: 15). This observation includes the dynamic character of knowledge, which could change with time and through transportation into different interpretational systems. Abel points to the problems that arise in translating knowledgein particular explicit, scientific knowledge-between various linguistic systems. As mankind has not yet found a 'best' way to organise such translation of knowledge between interpretational systems, we have to accept the plurality in the ways that knowledge is generated.

At this point, Abel also speaks about the 'best and creative brains' (2008: 16) that are necessary to elaborate useful translations between interpretational systems. Here, we can see that knowledge itself has a certain relation to creativity. Knowledge itself is not universally applicable, but it needs creativity to make it interculturally efficient for a knowledge society. I will return later to what relation exists between creativity and knowledge.

Let us go on with the notion of information. Abel (2008) explains that information is a common buzzword in the frame of social and technological change. He remarks that there is currently much confusion between the two terms 'information' and 'knowledge'. It is not clear anymore if we are living in a knowledge society or an information society. Thus, some clarification is necessary. In a fundamental understanding, information is a bridging process between physical cognition and phenomenal processing in the brain. This involves the logical consequence that information is always treated and processed through the lens of existing knowledge. Information has to be interpreted, and interpretation needs former knowledge. In opposition to the oft-suggested idea that information exists before knowledge in a person's lifeworld, Abel thinks that information does not exist independently of knowledge. Information only becomes 'information' when it is perceived and processed as such by a knowing human being (Abel, 2008: 17f.). Self-critically, Abel remarks that in certain spheres information can exist before knowledge, e.g. in public social opinions as transported in the media. However, I think that the basic model is more helpful to an understanding of the relationship between knowledge and information: information has to be perceived by human beings, it has to be processed using interpretation that actually relies on knowledge, and it can then become part of new knowledge.

What is the role of creativity then? An interesting overview of the philosophical understanding of the term is provided by sociologist Ulrich Bröckling. Bröckling (2006: 513) formulates: 'Creativity is tied to the human potential to bring into being something new. Its basis is, first, the power of imagination as the capacity to make the absent present; and second, building upon this, fantasy as the capacity to realize the (as yet) inexistent'. According to Heinrich Popitz, Bröckling explains that creativity con- 
tains three overlapping elements, which are 'exploration' (discovery, invention, new knowledge), 'shaping' (producing artefacts), and finally the 'generation of meaning' (interpretation, reasoning). We can see that such an understanding already contains links to the notion of knowledge. Creativity is, on the one hand, the production of new knowledge through exploration, but it is also the semantic and symbolic re-processing of existing knowledge into forms with new meaning and content.

Bröckling then describes six fields that can be used to develop a refined definition of creativity. First, creativity can be understood as artistic expression that is something innate to the human being. Second, creativity can be thought of as production process, referring to the relation between the human being and what they produce with their own work. This field is linked to an iconic understanding of the craftsman and artisanal handicrafts. In this understanding there is a connotation of self-actualization through work, which nowadays shows up again in the description of creative industries, although they do not necessarily manually produce goods. Third, if one focuses on the aspect of problem solving, then creativity is more related to invention and innovation. In their own lifeworld, human beings are continuously confronted with new situations in which routines and instincts do not suffice for an appropriate reaction to an unexpected situation. Thus, the unknown situation calls for a new and 'creative' way to deal with it. Bröckling mentions that the figure of the inventor is exemplary of this type of creativity. Fourth, creativity can also be related to the idea of revolution. The term creative destruction explains how people extend borders that were formerly thought of as intransgressible. A fifth field of creativity is articulated in the notion of life itself. Related to biological creation and evolution, creativity also contains an element of vitality, survival and adaptation. Finally, and sixth, creativity refers to the metaphor of play and purposeless activity. Bröckling concludes that creativity is the interplay of inventing the new and reshaping the existent.

'Creativity involves the ability to synthesize', says Richard Florida (2002: 31). Other than intelligence - which is the ability to deal with large amounts of data creativity serves to combine existing materials, things and concepts in a new and useful way. Florida mentions a four-step model that characterises creativity (2002: 33). During a creative production process, the first step consists of 'preparation'. This means that the creative knowledge worker studies a given problem by logical means. In the second step, called 'incubation', the creative knowledge worker's conscious and subconscious minds interrelate. Then, the creative knowledge worker realises a new synthesis through 'illumination'. And finally, this new synthesis is tested for its usefulness through 'verification and revision'. 'Creativity cannot be switched on and off at predetermined times', Florida mentions (2002: 14). Thus, in line with Bröckling, Florida also refers to the fact that creativity is always present in the life of each individual. Yet, he is convinced that creativity is also manageable and can have a cumulative effect: 'Creativity involves distinct kinds of thinking and habits that must be cultivated both in the individual and in the surroun- 
ding society. [...] It reflects norms and values. [...] Furthermore, creativity requires a supportive environment that provides a broad array of social and cultural as well as economic stimuli' (Florida, 2002: 22). Here, he suggests that specific contexts can lead to more creativity than other ones.

I will conclude this brief and somewhat cursory discussion of these three notions with the following observation: we can understand information as an input to the development of knowledge; and the process of making knowledge from information could be described as creativity. From that conclusion, it becomes obvious that the advent of the creative industries debate can be traced back to early scientific work dealing with how information and knowledge have influenced our post-industrial society and economy.

\subsection{Definition of Creative Industries}

In making creative knowledge workers the object of analysis in this book, it is important to have a look at the discourse of the definition of the sector and its workers. What is this whole discussion about? The basic problem with the definition of creative industries is that it is rather difficult to estimate how strong creative work penetrates the economy as a whole. As I discussed above, scholars of the knowledge economy have realised that there is an autonomous sector, but there is also knowledge work as part of other sectors such as automotive, chemicals, or food. The same accounts for creative input that is part of nearly all industrial goods, or even public services. Therefore it is not an easy task to define creative industries and make them distinguishable from other sectors. There is great variety between different scholars and their viewpoints. However, all the publications share the characteristic that they define creative industries in two ways. On the one hand, there is a rather 'soft' way-applying qualitative descriptions. On the other hand, scholars try to delineate creative industries in a 'hard' way through statistical analysis using standardised industrial or occupational classifications (like the ISCO or NACE schemes). I will briefly examine which definitions could be found in the literature before describing my own understanding in the framing of this book.

\subsubsection{Soft Definitions: The Qualitative Dimension of Creative Industries}

An important and early contribution was the book titled Creative Industries by Richard E. Caves (2000). Caves dealt with the question of how creative industries differ from other business activities and could thus be distinguished for analytical purpose. In particular, he stressed the different modes of the organization of production as compared to other economic sectors. Applying economic contract theory, he studied under which circumstances tasks were organised as in-house activities or as out-sourced 
market transactions. According to his definition, creative industries are those sectors (2000: 1) 'supplying goods and services that we broadly associate with cultural, artistic, or simply entertainment value. They include book and magazine publishing, the visual arts (painting, sculpture), the performing arts (theatre, opera, concerts, dance), sound recordings, cinema and TV films, even fashion and toys and games.' Caves explains that creative industries are to be distinguished from other economic activities. He writes (2000: 2): 'What I stress instead is that creative goods and services, the process of their production, and the preferences or tastes of creative artists differ in substantial and systematic (if not universal) ways from their counterparts in the rest of the economy where creativity plays a lesser (if seldom negligible) role'. Why is that? Caves describes seven basic properties of creative industries that make these sectors different from other economic activities.

First, the demand for creative goods and services is rather uncertain. Creative producers often do not react to an existing demand in the market. In many cases, they develop goods and services that can only be sold if the producers create the demand for their product along with the product itself. Thus, creative production is associated with strong uncertainty concerning the sales potential. It contains a high economic risk. In addition, creative products and services are 'experience goods' (Caves, 2000: 3). This means that the products' evaluation, following the consumption experience, is rather subjective and less predictable. The problem is not asymmetrical information - as in many buyer-seller-relations - but it is 'symmetrical ignorance': the seller does not have a clue about the expected demand of a creative product, and the buyer does not know what 'experience' he is going to buy.

Second, creative producers care about the quality and the reputation of their ouevre. While not all customers may be able to appreciate the quality of a creative product, creative producers also value the evaluations of their colleagues. Thus, creative producers put more effort into the production of a good than they are actually paid for. This problem is also linked to the first property because the problem of 'symmetrical ignorance' comes into play here. The creative producer does not know in advance if they have translated a great vision or concept into a creative product that is understood as 'great' by consumers, too. Often the creative producer's vision is not understood as such, and it does not pay off in financial terms (Caves, 2000: 3-5).

Third, the diversity of experts with different specializations who collaborate on the production of a creative product is an important aspect of creative industries. When many creative experts with individual (artistic) tastes have conflicting opinions about the product as a whole, then collaboration becomes a difficult issue. Often, these conflicts are not solved through formal contracts but through a 'rankorder mechanism of 'muscle", as Caves writes (2000: 5). Collaboration is also characterised by what Caves calls a 'motley crew property' (2000: 6), which in economic theory is known as the multiplicative production function. Whereas in a simple production function each individual input is substitutable, in creative industries this is 
often not the case. When individual inputs are highly specialised and unique, and thus a necessary piece to the output as a whole, then team collaboration is a decisive and constitutive element for a product's final realization. However, there is a double difficulty in terms of production teams: on the one hand, individualistic artist characters, who have very specific tastes and self-understanding, need to compromise with others who are similarly individualistic. Only through such collaboration can a complex creative product be elaborated. On the other hand, if one of these individuals is not satisfied with the compromise and quits the team, they cannot be replaced by another artist with a similar qualification-remember: 'their input was unique'-and the whole product will not likely be realised.

Fourth, creative products are often unique and less comparable than other products. Given the particularity that they have to be 'experienced' first, a consumer can only compare two creative products to each other (e.g. two movies or two songs) after having consumed them. Thus, ex ante pricing is very difficult. This horizontal differentiation of creative products, as economists term it, is causing the 'infinite variety property' (Caves, 2000: 6). Products are differentiated in a vast variety of unique appearances, but consumers, looking for similarities in order to compare prices, tend to overlook these differences. Thus, products that have low production costs will probably be compared and considered similar to very costly productions. The latter will then make lower profits or will remain unprofitable on the market, as consumers are not willing to pay a higher price to reach the profit margin targeted by the creative producer. The infinite variety problem is only limited by the 'first-copy costs' (Caves, 2000: 364), which are the fixed costs a creative output will have to produce a first edition to be marketed.

Fifth, there is also vertical differentiation between creative goods. Caves illustrates this aspect using the example of a movie production in which the producer will achieve a higher profit if they produced the movie with an A-list actor. Even though a B-list actor would offer the same service to the producer, they would not be contracted because the differentially lower sales would not allow the producer to make the film profitable. So creative industries are characterised by an 'A list/B list property', as Caves explains (2000: 7).

Sixth, there is the problem of temporal coordination of creative inputs from different creative agents. These consecutive inputs are necessary to achieve a creative output (e.g. in a movie production: the services of actors, cutters, special effect engineers, make-up artists). If a project is only in its initial stage and only some money has been spent, then a delay is no problem. Yet, at the moment when the production comes close to an end and production costs have been sunk, returns on investment should be realised as quickly as possible, as inflation devalues money with the passing of time. Thus, at the end of production it is very important that all inputs are available at the right time. This problem of coordinating inputs in a temporal sequence is called the 'time flies property' (Caves, 2000: 8). The temporal sequence of production inputs also comes along with another problem: those creative producers 
who provide their input at the initial stage of a project often lose control over the following production stages when other input producers have to provide their parts. As 'time flies' by, market information might change (e.g. information about an expected return), and consequently the project as a whole could be driven in a different direction. Thus, 'option contracts' are a common model to organise market transactions in creative industries (Caves, 2000: 8). In an option contract, the first input provider hands over the right of decision-making in the project to the second input provider. In return, this second input provider guarantees the first input provider that they will make a decision about how to proceed with the project within a pre-defined time frame, so that the first input provider could still hope for a profitable outcome and a speedy return on investment. Furthermore, the second input provider will negotiate with the first one to determine how much the first one will be rewarded for their input. The same transaction occurs between the second and third input provider, and so on.

Finally, there is the question of the durability of creative products. The main mechanism to realise profits is the copyright, and copyrights have a certain temporal duration according to the legal system. This fact is called the 'ars longa property' (Caves, 2000: 9). The major issue is how the copyright fees can be collected if they occur in form of numerous small units, with costs attributed for the maintenance of the copyright ownership. Another question concerns the share of this profit that is guaranteed to each input provider of a complex creative product. This amount is often only an estimate, and thus shares are difficult to calculate.

These seven basic properties affect the organizational structure of creative industries. Caves remarks (2000: 16): 'In the creative industries these diverse groups of market competitors turn out to reflect the basic properties of creative goods. For example, the inner and individualistic aspect of creative production mixes badly with the orderly, rule-driven routines of the large, bureaucratic firm. Creative industries tend to be organized so that the most delicate dealings with artists concentrate in small firms specialized to this task, while other firms (usually much larger ones) undertake to combine creative work with large teams of humdrum inputs.'

These many small creative firms with high degrees of specialization then need gatekeepers who match them with potential clients. The gatekeepers have power because they can decide which individual small firm or artist to promote in a preferred manner. Many small producers in creative industries who have not yet established good relationships with powerful gatekeepers, or who have trusted in powerless gatekeepers, find themselves in a precarious situation. Caves writes (2000: 363): 'The many would-be creative workers who suffer rejection [from the right gatekeepers] either toil in dedicated poverty or settle for humdrum work, while those who experience creative success reap adulation and wealth in what tend to be winner-take-all contests.' In other words, entry barriers for individual creative workers are very high because large-scale distribution systems in creative industries are mainly organised in oligopolistic structures. A common solution to this problem is 'payola'. In order to get good 
access to the market, payola is the practice of paying for market entry in informal ways. Payola is a way of corrupting gatekeepers to ensure the promotion of newcomers' creative products (cf. Caves, 2000: 286-296).

Some properties of the creative industries are part of other economic sectors, too. For example, the way in which information flow is organised resembles that of academic work environments (Caves, 2000: 367): 'In complex creative industries, a great deal of information flows within and among firms - the A list/B list ranking process and the jostling over nascent projects that might or might not prove successful. [...] Academic researchers in the social and natural sciences conceive of the research process essentially the same way as do creative artists - as a way of identifying new problems of substantial importance and devising compelling solutions to them. Scholarly researchers assign high value to an open culture with unfettered exchange of information.' It becomes obvious here that certain characteristics are similar to mere knowledge work (e.g. science or research and development), as understood before the rise of creative industries/creativity as scientific topic (cf. section 2.1).

With his book, Caves provided a sound effort to characterise creative industries. He developed in detail his seven properties to differentiate creative industries from other economic activities, and he also described internal differentiation within creative industries (which I have left out in favor of brevity). Regardless, he remained vague about which economic activity in detail should be included in or excluded from the creative industries. He did not specify individual sectors, but only named exemplary activities. On the other hand, he remained rather narrow in his definition and observations described in the book: he only focused on artistic production and understood creativity as a creation process in an artistic sense (cf. Bröckling, 2006, as in section 2.1.4).

The definition in Richard Florida's books (2002; 2005) is equally fuzzy, because for Florida the notion of 'creative class' is central. He prefers to speak about the actors instead of the industrial sectors. According to him, creative industries are composed of 'people who are paid principally to do creative work for a living. These are scientists, engineers, artists, musicians, designers and knowledge-based professionals [...].' (Florida, 2002: xiii). It is obvious that Florida included far more activities than Caves, talking about more professionals than only artists. However, Florida's notion of class has to be questioned as it varies significantly from that of the traditional sociologists such as Marx. For Florida, a class is determined by a group of people 'who have common interests and tend to think, feel and behave similarly, but these similarities are fundamentally determined by economic function' (2002: 8). Thus, a class - according to Florida - is already a class when people do the same job and develop similar interests. In Marx' notion, a group of people form a class through collective identity and collective agency. This is certainly not true for creative professionals, as Florida, a self-proclaimed Marxist, notes himself (2002: xxix). What defines Florida's creative class is the job for which it is paid, namely to 'create', in a work environment highly valuing individuality, difference, autonomy, flexibility and merit. Distinguishing 
from the creative class, Florida speaks of a 'working class' and a 'service class', whose members mainly 'execute' commanded work.

Within the creative class, he identified a 'core of creative workers', who create new ideas, technology and content. Surrounding this core, there are the 'creative professionals' who do jobs in which independent judgment and higher education are necessary inputs, and who have to apply the innovative knowledge created by the core of creative workers. According to Florida (2002), creative workers prefer selfexpression, diversity and open-mindedness over homogeneity and conformity, with the latter two having been necessary in much of other manufacturing and low-end service work. Furthermore, challenging tasks, responsible positions and flexible schedules are important job-related aspects for creative professionals. Even though the term 'creative class' leaves much reason for criticism, it has also become famous across Europe (cf. Marlet \& van Woerkens, 2007).

The European Commission followed the UK Department of Culture, Media and Sport (DCMS) in elucidating that creative industries 'have their origin in individual creativity, skill, and talent and [...] have a potential for wealth and job creation through the generation and exploitation of intellectual property' (DCMS, 1998; cited in European Commission, 2010b: 191). It is interesting to see here that the notion of intellectual property is mentioned as a way to generate rewards and profit. This reflects the UK DCMS' understanding that creative industries, in order to be an industry, must be profit-oriented and part of the private sector. The European Commission also acknowledges the potential of creative work that takes place in other sectors (European Commission, 2010b: 198): “Creative occupations' is a broader concept than 'creative industries'. It embraces the professions that are 'creative' in essence, no matter whether they belong to the so-called 'creative industries'. [...] These 'knowledge workers' produce intangible assets such as ideas, knowledge, and information that increase firms' value added.' Here again the link to the knowledge economy shows up. The penetration of brain work into other economic sectors as well as the general importance of knowledge creation is emphasised.

In its Green Paper, Unlocking the potential of cultural and creative industries, the European Commmission writes (2010b: 2), 'In this new digital economy, immaterial value increasingly determines material value, as consumers are looking for new and enriching 'experiences'. The ability to create social experiences and networking is now a factor of competitiveness. [...] the rapid roll-out of new technologies and increased globalization has meant a striking shift away from traditional manufacturing towards services and innovation. Factory floors are progressively being replaced by creative communities whose raw material is their ability to imagine, create and innovate.

There is a broad variety of other qualitative descriptions of the character of creative industries. I will not go further into detail here, because this section does not aim at a refined definition. Yet, I believe that this brief presentation of some ideas about creative industries helps to portray the specificity of this sector as compared to 
other economic sectors. Let us keep in mind that creative industries predominantly engage in immaterial production: they solve problems through innovation, creation and imagination. Creative outputs can be emotions, experiences, concepts, values, or formal knowledge. They are composed of small and independent production units, which gather in flexible ways in highly unique and specialised teams around fixedterm projects. Therefore, networking is an important issue in order to bring together the necessary skills at the right moment, but also to ensure quality through powerful network-based reputation systems. Furthermore, the creative industries are an economic sector in which market risk is asymmetrically heavier a burden to the many small producers, while a few large corporations-Caves' gatekeepers-control distribution and access to sales markets. Finally, there are a few individual stars in creative industries who claim a large share of profits, whereas a large majority of creative knowledge workers have to divide the rest. I think we have to keep this in mind when reflecting the situation of creative knowledge workers later in the empirical analysis section (chapters 7 \& 8).

\subsubsection{Hard Definitions: The Quantitative Dimension of Creative Industries}

In addition to these qualitative descriptions of creative industries, the literature also reports attempts to define this economic sector in quantitative terms. I will call these attempts 'hard definitions' as they rely on the use of statistical data. With hard definitions I mean the different selections of statistical codes extracted from the standardised economic statistics. Yet, I am not interested in discussing statistical hard definitions in detail in the course of this book. I have been involved in projects where this was an issue, but I do not think it is necessary within the framework of this book as the main research questions are not about quantification. Despite this, I will try to illustrate the size and quantity of the 'creative industries' phenomenon by referring to statistical figures that are mentioned in several studies. The most common databases are labour statistics, which use a nomenclature of occupations (e.g. ISCO - International Standard Classification of Occupations), as well as business statistics, which use a system of industrial codes (e.g. NACE - Nomenclature statistique des activités économiques dans la Communauté Européenne). The composition of creative industries according to classification codes varies greatly from author to author. Thus, it has to be mentioned that numbers are not directly comparable between individual studies and they have to be interpreted with caution.

Howkins (2001) provides a wider definition of creative industries that is orientated towards concrete industrial sub-sectors. According to his definition, the following sub-sectors have to be considered as parts of the creative economy: Research and development, publishing, software, TV and radio, design, music, film, toys and games, advertising, architecture, performing arts, crafts, video games, fashion, and art. In 1999, these sub-sectors had a global market size of US\$ 2,240 billion, out of 
which the US creative industries held 43\% (Howkins, 2001: 116; cited in Florida, 2002: 47). It becomes obvious that this definition is more inclusive than Caves' understanding of creative industries. Scientific activities and crafts are considered a part of creative work, too.

Richard Florida also prefers an inclusive way of defining his 'creative class', even though he declines to define these industries along traditional industrial classifications (Florida, 2002: 327-329). 'According to Florida, nearly all activities that have to do with 'brain work' are included. Florida distinguishes his 'Super-creative Core' from other 'Creative Professionals' (2002: 328). The former group is dominated by occupations in the scientific fields and in engineering, but it also includes the artists, designers and entertainers. The latter group contains occupations that deal with the provision of more complex services to other businesses and private clients. Florida tries to list specific occupational groups. According to him, scientists, IT specialists and engineers are also part of the creative class because they develop and create new knowledge and information. Furthermore, managers, lawyers, financial professionals, health care personnel and even salespeople should be included as well. These 'creative professionals' are applying existing knowledge in innovative ways, thereby improving applied knowledge through small innovations. Allowing for this openness in the definition, Florida calculates that 38.3 million workers in the US constituted the creative class in the early 2000s. They accounted for a $30 \%$ share in the total labour force. Florida is convinced that the phenomenon is a rather recent one; the creative class has grown in particular since 1980 (Florida, 2002: 74ff.). However, there is also widespread criticism concerning this openness in his definition, as there is evidence for multicollinearity between human capital (as measured by education levels) and the share of creative class in a place. This drives critics to the conclusion that such a wide definition, as that of Florida, which includes nearly all high-skilled professionals, does not produce any benefit for the explanation of regional economic growth (cf. Markusen, 2006; as cited in European Commission, 2010b: 214).

Whereas in the USA the discussion about a proper definition of creative industries focuses on the agents themselves-the creative knowledge workers or the creative class (cf. Florida, 2002)-European scholars tend to refer to economic sectors and use NACE and ISCO code combinations. The ESPON 2013 Programme Coordination Unit (2011) recently published a report on Europe's creative workforce. Here a set of 42 different ISCO-88 4D codes has been used to define the creative workforce (cf. Appendix). As in the definition of Howkins, crafts as well as scientific research and teaching are included in creative industries.

In its 2010 Competitiveness Report, the European Commission (2010b) uses a more limited approach, excluding scientific sectors. Here crafts are still considered part of the creative industries. The UK government follows this manner of narrowing the sector and uses a very selective definition. In this definition scientific activities as well as research and development are excluded. Non-profit activities are also not 
counted as creative industries, as industrial activities should have a clear 'economic' character.

In its Green Paper the European Commission defines the 'cultural' industries (European Commission, 2010c) by listing eight sub-sectors: artistic and monumental heritage, archives, libraries, books and press, visual arts, architecture, performing arts, and audio and audiovisual media/multimedia. These sectors are also used by Eurostat for statistical analyses. Furthermore, a functional distinction is introduced in this definition; cultural industries could also be grouped according to their purpose. Here, the dimensions of preservation, creation, production, dissemination, trade/sales and education are mentioned (European Commission, 2010c: 5). In contrast to the European Commission's Competitiveness Report, the Green Paper applies a rather broad approach in defining cultural industries following the 2005 UNESCO Convention on the protection and promotion of the diversity of cultural expression. Here, the European Commission (2010c: 5f.) says, “Cultural industries” are those industries producing and distributing goods or services which at the time they are developed are considered to have a specific attribute, use or purpose which embodies or conveys cultural expressions, irrespective of the commercial value they may have. Besides the traditional arts sectors (performing arts, visual arts, cultural heritage including the public sector), they include film, DVD and video, television and radio, video games, new media, music, books and press.' In addition to these cultural industries, there are 'creative industries' which 'use culture as an input and have a cultural dimension, although their outputs are mainly functional. They include architecture and design, which integrate creative elements into wider processes, as well as subsectors such as graphic design, fashion design or advertising' (cf. European Commission, 2010c: 6).

In the logic of the Competitiveness Report 2010 (European Commission, 2010b), creative industries are divided into three sub-sectors: information services (publishing, new media, software), business services (architecture, engineering, advertising, design, photography, translation and interpretation), and arts and entertainment. According to the European Commission, the dominant sub-sector, which is the motor of creative industries, is information services. These information services accounted for $62 \%$ of creative industries employment in the EU-26 (Malta excluded) in the year 2008. Business services made up 29\% of creative industries' employment, and the third sector, arts and entertainment, only makes up roughly $10 \%$. As such, there is a strong internal differentiation with respect to the importance of sub-sectors within the creative industries.

According to the Competitiveness Report 2010 (European Commission, 2010b: 191ff.), approximately 6.7 million people worked in the creative industries in the European Union (EU-27) in 2008. Thus, 3.0\% of the total employment is creative knowledge work (compared to $4.0 \%$ in the USA). The higher share in the USA can be explained by the large audiovisual and computer software sector, which exceeds the European one. In terms of external exports from the EU-27, creative industries account 
for $4.3 \%$, and make up about 3.3\% of the total GDP. In the period from 2000-2007, employment increased annually by 3.5\%, while total employment in the EU-27 grew by only $1.0 \%$. In the US and China growth rates were smaller, with $1.8 \%$ and $1.9 \%$ respectively. The European Commission also highlights that there is internal difference concerning the growth rates, with software consulting and supply, audiovisuals, and architecture recently growing faster than other sub-sectors of the creative industries. Computer programming and consulting also make up 37\% of EU-27 total employment in creative industries, followed by architecture (15\%). Employment figures here are based on people employed by creative companies (selected according to industrial codes).

However, there are also creative workers in other industrial sectors. These could be identified by using labour statistics and the occupational classification system, in which workers are not registered as belonging to a company but to an occupational group. The European Commission reports that roughly $62 \%$ of creative occupation takes place outside the creative industries (2010b: 198). Calculating occupational instead of employment shares, they state that in 2008, in a selection of 15 EU countries for which Labour Force Survey data was available, 7.7\% of people were occupied with creative knowledge work. The most important professional groups concerning occupation are architects and engineers. Between 2002 and 2008, there was a growth in total creative occupation by $3.1 \%$, with the highest growth for artistic and entertainment professionals as well as social scientists and related professionals.

The recent economic and financial crisis, which began in 2008, has also affected the creative industries. In particular, sub-sectors with a strong share of business-tobusiness (B2B) activities experienced a downturn: advertising's turnover decreased by $12.4 \%$ from 2008 to 2009 in the EU-27. Publishing turnover also decreased by $6.8 \%$ as advertising budgets were cut during the crisis. In terms of both employment and turnover, the creative industries in the EU-27 experienced their first decline in the past 10 years, with a decrease of 3.3\% in employment and 9.9\% in turnover (European Commission, 2010b: 200f.).

National and regional governments have discovered the issue of creative industries, and recently economic as well as cultural affairs' departments and ministries have been rushing to 'count' the extent of creative industries in their own jurisdictions. Here, we can observe that 'creativity' is inherent to this process itself: governments use rather individualistic and poorly comparable definitions. For example, a national definition was agreed upon in Germany. This definition includes all economic activities in the fields of music production and interpretation, book authorship and publishing, fine arts production and trade, television and radio broadcasting, performing arts, design activities, architecture, journalism, advertising, the software and games industry, and finally the catch-all sector of 'miscellaneous cultural activities' (e.g. circus artists, museums, libraries) (Söndermann et al., 2009). Despite this national consensus, regional governments' definitions still vary widely from the national one. Some regional governments prefer wider definitions, e.g. the government 
of Saxony also includes craftsmen and producers of musical instruments (SMWA/ SMWK, 2009).

To sum up, the presented definitions and figures highlight two primary aspects: first, just as with the 'soft' qualitative definitions, there is a large variety between individual 'hard' definitions using statistical classifications. Again we find broader and more inclusive definitions along with more exclusive approaches. Thus, it is rather difficult to precisely distinguish creative industries from other sectors that are closely related to the creative industries. I will leave this as an observation and I am not tempted to develop my own solution to that problem here. Second, there is an even more important point in the literature: independent of the definitional issues, several authors have come to the conclusion that creative industries represent a very dynamic segment of the labour market. Even though the sector is still a rather small one, there is some empirical evidence in most figures that creative industries are becoming more important in relation to other economic segments. Above average employment growth has come along with a comparably smooth performance during the financial crisis, and both of these facts make creative industries an interesting field of research for the coming years. With arguments I would definitely support, some critics point to the neoliberal and oppressive character of these sectors. Others even try to diminish the 'creative industries' phenomenon to a mere product of discursive construction by certain interest groups ${ }^{6}$. So, I would say that we still do not know enough about the creative industries and we cannot renounce making it a topic. We still do not know if these sectors will turn out to become a stable, long-term growth machine for postindustrial economies or not. And even if we were already sure about their long-term stability, we would need to study in more detail what their presence means not only in economic but also in social terms.

\subsubsection{Public Sector Activities}

There is an ongoing debate about the role of public activities in the creative industries' markets. A share of creative institutions, e.g. opera houses, orchestras, theatres, etc. are to a large degree financed with public money. The same holds for museums. The question is then, do these activities reflect market participation, or is it part of the state's public activities? There are different opinions about this issue.

For example, both the UK government and the UNESCO use definitions in which a distinction between economic and cultural activities has been introduced. I mentioned above that the European Commission (2010b) pointed to the UNESCO position

6 This argument is used by representatives of traditional industrial sectors who do not believe in an independent existence of a creative sector in the economy. Their idea is that creative activities have always existed as a part of other industrial sectors. 
when saying that cultural goods and services are those that are provided 'irrespective of the commercial value they may have' (UNESCO; cited in European Commission, 2010b: 193). In the UK, the DCMS changed the notion of 'cultural industries', which was used earlier by the UK's Labour Party, into the term 'creative industries'. The DCMS underlined that cultural services would exclude a broad range of knowledge services that were formerly termed 'new economy', and which made up a large share in economic power of the creative industries. Based on ideas by Meusburger et al. (2008), the European Commission writes (2010b: 193): 'While creative industries link creative content to job and wealth creation, cultural industries are not first and foremost defined by their business value.' The UK DCMS even goes further and finally excluded non-profit activities completely from its definition (European Commission, 2010b: 194).

Another approach consists of the 'three sector model' which evolved in Switzerland in the context of the first national creative industries reports. Here, the distinction is made between merely public and private sectors. Additionally, a third sector is introduced which includes activities at the intersection between both other sectors. For Swiss policymakers and scholars of creative industries, the creative industries are mainly the private sector, which is profit-oriented. The other two sectors, public and intermediary activities, mainly operate in non-profit fields. They are strongly linked to the private one, as, for example, individual actors often work in all the three sectors. Thus, from the perspective of the creative professionals these three sectors work as a compound system. Yet, for analytical ambitions the sectors should be divided, and only the economically-oriented sector should be examined in detail (Weckerle et al., 2008: 28).

\subsubsection{Insertion of Creative Industries into the Wider Market}

After having described the content with which the creative industries deal, and the extent to which they are in place today, I would like to mention some points which are relevant in understanding how the creative industries relate to other sectors. We have already heard a bit on internal structures in creative industries in the ' 7 properties' by Caves (section 2.2.1). However, there are some interesting additional observations concerning the insertion of creative industries into the wider market.

\section{Intersectoral business relations}

Creative work is not only limited to creative industries. Florida (2002) remarked that there is an ongoing penetration of creative work into other industrial sectors. What he calls the 'rise of the creative class' or the emergence of an 'Age of Creativity' is also visible in the change of tasks and qualification levels in the economy as a whole. Equally, the European Commission mentions that 'creative workers can also be found in other skill-intensive manufacturing or business services activities’ (2010b: 191). 
A large share of creative occupation could be found in sectors other than creative industries as defined by selected NACE codes.

Additionally, creative industries are closely interrelated with other industries through value chains. From UK data, it is known that business-to-business relations of creative industries with other sectors account for $60 \%$ of their total output. In particular, intermediate services and products are provided by the advertising, architecture, software and fashion sub-sectors. Other sub-sectors such as radio and TV, the film industry as well as the arts sector are mainly orientated to private consumption and business-to-consumer relations. The EU Commission's Competitiveness Report reveals that $80 \%$ of turnover in software and $93 \%$ of turnover in advertising stem from business-to-business transactions (European Commission, 2010b: 216).

A Danish study recently examined the client structure of creative business-tobusiness transactions. Using creative industries' shares in intermediate inputs to a sector, it was found that creative industries themselves were the main consumer (with $37 \%$ of all inputs consumed from other creative businesses), followed by the real estate sector (22\%, mainly buying from publishing and software companies), the adult and other education sector (21\%, mainly consuming audiovisual services), and tobacco and beverages (17\%, mainly buying advertising services) (European Commission, 2010b: 217/246).

Also the increasing knowledge spillovers from creative industries to other sectors highlight the relevance of these creative activities. The European Commission remarks (2010b: 218): 'Creative industry firms tend to make use of a large network of weak, heterogeneous relationships that ensure easy access to and fast absorption of new knowledge - an observation which fits well with the evolutionary/systemic view of innovation.' Thus, non-creative companies having business relations with creative companies can profit from this character. Creative industries are attributed external innovation effects that make companies outside the creative sectors more innovative when they have strong links to creative businesses. Based on UK data, Bakhshi et al. (2008) found that non-creative businesses which double their spending on creative products and services from $3 \%$ to $6 \%$ are $25 \%$ more likely to innovate their products (cf. Bakhshi et al., 2008; cited in European Commission, 2010b: 222).

In the European Commission's Green Paper, we find another hint to the reinforced importance of existing links between creative industries and external sectors (European Commission, 2010c: 7): 'The global digital shift reinforces the position of important stakeholders such as telecom companies or consumer electronics manufacturers, and coincides with the emergence of new strong global players such as search engines and web based social platforms which - while making significant contributions to the development of the market place - can potentially act as new gatekeepers.'

Based on a paper by Chartrand (1984), the authors of the Competitiveness Report list four different types of impact that the creative industries can have in economic and social spheres (European Commission, 2010b: 192). The primary effects could be 
measured directly in terms of employment, value added, or exports which are rooted in creative industries themselves. The secondary effects could only be observed indirectly. For example, economic spillovers to other industrial sectors stem from creative industries' capacity to provide important intermediate goods and services for other businesses, which help these other businesses to grow. Particularly in light of a growing importance of branding and invidualising consumer goods, creative industries help traditional manufacturers add value to their products. Tertiary effects evolve from spillovers of innovation (e.g. process innovation, new ideas, creative input) to other sectors. These effects are not quantifiable but can have a major impact on how non-creative businesses produce and sell. Often creative businesses are contracted for a certain task by large traditional companies, and even after the paid service is delivered, the commissioning company can profit from knowledge spillover and innovation acquired during the collaboration with a creative supplier. Quaternary effects are even harder to observe as they are both indirect and non-quantifiable. These effects include the general augmentation of the quality-of-life in a certain place through innovative ways of organizing the economy and the society. In particular, the provision of cultural services and the innovating impact on traditional values and norms can be mentioned here. Also the production of symbolic meanings (e.g. through the development of place-based or group-based identity concepts, lifestyles, images, etc) represents such a quaternary effect.

\section{Internal market structure}

As mentioned above, company size distribution in creative industries shows a specific pattern, which is relevant for how the market itself works. According to the European Commission's Competitiveness Report (2010b), about 95\% of all creative businesses have only up to 9 employees, compared to $80 \%$ in traditional manufacturing sectors. Self-employed people make up $58 \%$ of the total creative industries businesses, with advertising having at $67 \%$ the largest share of all creative sub-sectors. Translated into employment statistics, this means that $35 \%$ of creative workers are employed in micro firms with less than 10 employees, and 13\% of creative workers are self-employed. In the European Commission's Green Paper the situation in creative industries is described as follows (European Commission, 2010c: 7): 'the vast majority of the CCI's [cultural and creative industries] consist of a myriad of micro-, small and medium sized enterprises, as well as freelancers, co-existing with vertically or horizontally integrated companies. [...] They are typically the risk takers and early adopters and play decisive roles when it comes to scouting for new talents, developing new trends and designing new aesthetics.'

Another interesting fact is that creative industries have strong internal supplychain linkages between different sub-sectors. The European Commission (2010b) observed that in particular the advertising and publishing sectors are intertwined. The media sector and relevant content providers (independent writers, journalists, and photographers) also have strong business connections. Thus, creative indus- 
tries are partly a self-referential sector in which only certain sub-sectors link to external markets. This is also reflected in the relatively high share of internal business-to-business consumption. In 2004 in the UK, 19\% of intermediate purchases of creative businesses were bought from other creative businesses, accounting for $8 \%$ of the total gross output of the creative industries (European Commission, 2010b: 216). Interestingly, the large and important creative sub-sector of software consultancy and supply shows very few internal linkages to other creative sub-sectors (European Commission, 2010b: 202f.). It could therefore be questioned to what degree these activities should be included in the creative industries. At the least, it is obvious that the software sector has a specific and unique role within the creative industries: it is the largest activity and the least connected to other creative subsectors.

Furthermore, the European Commission points to some patterns in creative industries' markets that could be interpreted as market failure and which would legitimate policy intervention (European Commission, 2010b: 223f.). First, comparably to Caves (2000), the European Commission identified the 'speculative character' of revenues in uncertain markets as a major threat to the large group of micro firms and selfemployed workers. The low predictability of earnings makes decision-making very risky. Second, creative businesses' revenues are mainly based on first-mover advantages in the markets. But as creative goods and services consist to a large degree of concepts, ideas, knowledge and information, these could easily be stolen or copied before being released to the market. A central problem is to find investors without 'whistle-blowing' one's own idea. Therefore, traditional market-based finance models still do not sufficiently work, and public financial assistance as well as a better coordination of venture capital provision is necessary, as the European Commission concludes (2010b: 223).

\section{Interrelation with society}

Creative goods and services are also subject to strong externalities - both in production and consumption. Value is created mainly through interaction with society. A creative good increases in value when it is used by a large share of people, and when it gains symbolic value in the society. This implies that market price mechanisms are dysfunctional, and the collection of rewards is a complex issue. Here, the EU calls for a more pronounced discussion about the regulation of intellectual property rights. There is a large and negotiable continuum of practices for the management of intellectual property rights (IPR) between the two poles of rigid copyright protection and Creative Commons licenses/open access policies (see European Commission, 2010b: 224). Similarly, the European Commission argues in its Green Paper (2010c: 6): 'Economic value is being displaced towards the end of the chain, which in certain sectors affects the effective reward for creation. Moreover, parts of the content industries, particularly the recorded content industries, have been severely hit by piracy and losses in sales of physical supports (e.g. CD, DVD), which have damaged 
their development, shrunk their revenue basis and consequently limited their potential to generate jobs and investment. This is why the industry also needs to develop new and innovative business models.' From a conservative perspective, this could be read as a call for more rigid regulation of access to creative content. From a more progressive perspective, it sounds like a call for new ways of financing creative businesses. Yet one thing is clear: making money in creative industries works differently than in non-creative sectors.

The product itself is no longer the only issue for a creative company. In creative industries the emotional and symbolic loading of products is also important. With ongoing individualization and diversification of lifestyles, group identities, and individual behaviour, target group-specific marketing strategies and product images have become at least as important as the product itself.

New forms of value-adding are being developed in which the product is no longer sold, but rather leased or rented for a certain time. This business model responds to more mobile and flexible life styles. It led the US sociologist Jeremy Rifkin to speak of the advent of the 'Age of Access', in which material property becomes less important but the access to a variety of products and services is the new key issue and drives growth and prosperity (Rifkin, 2001). According to Rifkin, prosperous businesses often are not paid anymore for delivering a product or providing a service, but rather they earn money through selling access to knowledge, ideas, innovation, or even to emotions. Thus, a growing share of economic activity is no longer concerned with trading material goods. There is a certain dematerialization of economic activity, and the main source for remuneration becomes intellectual property (cf. the European Commission, 2010c).

Furthermore, the temporal aspect changes: product life cycles and market trends are becoming shorter. This means that research and development of new and innovative products are more important than ever and have to be more rapid in order to keep pace with the market. Knowledge has become a crucial resource for the development of new products and services. Thus, analytical tasks are a growing field of activity. Theoretical anchor points like the knowledge society or the information age (cf. Castells, 2000b) are helpful to contextualise the development of creative industries theoretically. But creative industries go beyond these two concepts for they not only focus on technological innovation and the development of abstract process-related knowledge, the also concern themselves with the development of emotions, values, norms and symbolic meaning. Creative knowledge work goes beyond mere economic interests and touches broader societal issues, as can be seen in the increasing interest in social entrepreneurship, social innovation and the growth of ecological and fairtrade economies (Ehrlich \& Lang, 2012).

In sum, creative industries represent a growing economic sector in post-industrial countries. They are heavily interrelated with traditional economies. One might even argue that the globalization and ICT-induced outsourcing processes made creative industries more visible as a separate economic sector and helped to boost its emer- 
gence $^{7}$. Formerly, creative knowledge work was often a small part of large industrial conglomerates (and still remains so to a certain degree today). It was rather difficult to estimate the amount of creative knowledge work through available statistical data. Today, the outsourced activities have led to the creation of new companies and jobs, which have specialised in creative knowledge work and are visible as independent players on the market. These creative activities heavily influence the wider economy as well as society. The internal organization of companies as small units brings both risk (e.g. unpredictability of revenue, low market regulation, poor availability of venture capital) and opportunity (e.g. freedom from stasis and bureaucracy, flexibility allowing for creativity). So far, I have outlined how the creative industries as an economic sector are characterised. Section 2.3 will place the emphasis on the character of creative knowledge work and the typical description of the creative knowledge worker that can be found in the literature.

\subsection{The Creative Knowledge Workers and their Work Environment ${ }^{8}$}

Creative industries provide income to a growing share of Europeans (Wedemeier, 2010). Furthermore, creative industries are considered an interface between the formerly opposed systems of capitalist business-making and the idealistic world of free and independent artists and their oeuvre. These two opposing perspectives are increasingly merging, and the creative industries represent the arena where this rapprochement is being played out. On one hand, it is no longer about mere artistic freedom and independence from capitalist necessities, but also about how artists can capitalise on their own work (Friebe \& Lobo, 2006). On the other hand, the post-industrial economy has to accept that standardised mass consumer goods are not sufficient anymore. Due to the individualization of consumption habits, customised and individualised products and small-scale series have to be offered, which become more important for the generation of value-added (Friebe \& Ramge, 2008; Sennett, 2008).

Here, a new type of actor is about to assist this merging of the two worlds of arts and the economy. The so-called 'culturepreneur' is dominating both of these fields (Lange, 2005; Lange, 2007). They know how to create new and innovative services and products, but they are also aware of the fact that they have generated a 'product' and not a pure artistic oeuvre. This includes reflection about commercialization. Cha-

\footnotetext{
7 This argument cannot be discussed in more detail here. However, interested readers can enter into the debate around this idea by reading Sennett (2006).

8 Main parts of this section were published earlier in a working paper that I have written in the frame of the $\mathrm{PhD}$ research at the University of Milan-Bicocca, and which I presented in a slightly revised version during the 8th European Urban \& Regional Studies Conference 15-17 September 2010 in Vienna/Austria. The conference paper can be accessed here: http://www.dur.ac.uk/resources/geography/ conferences/eursc/17-09-10/RobertNadler.pdf (accessed 14 April 2014).
} 
racteristically, these culturepreneurs are successful in market niches, which they have actively developed with the emergence of the Internet and new modes of e-commerce. They are also capitalizing on highly flexible and specialised fields which result from the ongoing outsourcing process in the industrial sectors (Sennett, 2006). Yet, one question remains: how is it to work in these new fields? To answer this question, we should reflect the main characteristics of creative knowledge work in the light of the character of the industries as mentioned in sections 2.1 and 2.2.

\subsubsection{Immateriality and Brain Work}

Creative and knowledge intensive work is first of all 'brain work'. It could be defined as 'labour that produces an immaterial good, such as a service, a cultural product, knowledge, or communication' (Hardt \& Negri, 2000: 290; cited in Hesmondhalgh \& Baker, 2008: 98). It is clear that not all creative knowledge workers share the same degree of 'brain work', but creative knowledge work consists much more of reflection, innovation, and invention than work in other more traditional sectors where material production and more standardised tasks dominate. So, the remuneration of creative work faces the problem of how to fix prices. Whereas in material production piece rates are easily calculable and negotiable, prices for immaterial production and intellectual work are more difficult to define. At a first glance, this might seem a trivial observation, but it defines the economic power relations of the entire creative and knowledge markets. We should remember Drucker's ideas concerning the new struggle of the knowledge worker: they have the power of knowledge, but not of the knowledge's productivity. The economic value of intellectual output is difficult to estimate, as one performance could not easily be compared to another. Remuneration schemes thus stay poorly transparent. Christopherson (2008) documented how, for example, in the cable TV production sector the power relations and price fixing are strongly defined by the TV channel owners. This heavily affected income opportunities of freelance suppliers in TV production.

\subsubsection{Symbolic Contents and their Distribution}

Gill \& Pratt (2008: 9) recall that - for distinguishing creative work from other work there is the 'importance of symbolic production'. This means that in creative industries the production of basic knowledge is expanded to the provision of interpretations of this knowledge. Producing creative output frequently means producing lifestyles, identities and meanings. Lange \& Mieg (2008: 233) conceptualise creative industries as 'regionally differentiated markets of meanings in which the production and exchange of culturally relevant, symbolic values or goods is inscribed'. Also, Hesmondhalgh \& Baker (2008: 101) agree 'that the terms 'cultural' and 'creative', as 
applied to industry and work in recent policy discourse, have been centred primarily on symbolic, expressive and informational creativity'. This means that a large share of creative knowledge work is composed of not only thinking up new things but also giving them a meaning.

This production of meaning or symbolic value could easily be copied or claimed and redefined by others. Creative knowledge products and services, contrary to traditional mass production, add in value with their distribution. Once an idea, a concept or a lifestyle is accepted and used by a broad mass, it becomes dominant. Its 'creator' can expect large revenues. Yet, the access to large-scale distribution is difficult to achieve for an individual producer within the creative industries. Gatekeepers (e.g. a publishing company, a music label, a film producer) might refuse to support distribution. Second, there might be competing ideas, concepts and lifestyles that might interfere and interrupt the ascent of others. As such, there is a dilemma between efficient distribution and keeping control over the symbolic value and its commercialization. A good example is the music industry in which the digitalization caused massive problems in market organization. The copyright question is linked to this - with positions reaching from 'no copyrights' to stronger regulation (see also description in section 2.2). Another example for the relevance of market dominance in this 'winner-takes-all' competition can be found in the academic debate on creative industries itself: Richard Florida placed his books and presentations at the intersection of academia and popular science, reaching a huge audience. Even though in academia there are many studies that are elaborated in more sophisticated ways, it is Richard Florida who has become an iconic figure of creative industries research. He is booked worldwide for presentations and speeches in the fields of business development, urban planning, scientific research, etc. His idea of the '3Ts' - technology, tolerance, and talent - became repeated throughout the world. Having a publishing house with a powerful marketing machinery selling his books made him a winning figure. At the same time, other creative industries scholars, who developed what are likely more robust and reasoned ideas about the creative industries, did not succeed in the same way.

Thus, one major aspect of creative industries is how a creative knowledge worker gets his symbolic content noticed. The best idea in the world does not help the creative knowledge worker if no one becomes aware of it, or if no one relates its origin to exactly this creative knowledge worker. Here, we can surely relate to Austrian urbanist Georg Franck (1998), who elaborated a draft of what he calls Die Ökonomie der Aufmerksamkeit (Attention Economics). The basic idea of Franck's approach is that attention is a new and very important currency in a world dominated by information and mass media. Attention is a scarce good which can translate into financial value, but also into other forms of revenue (e.g. fame, recognition). In an information society in which immaterial production in the creative industries is becoming more important, attention is a central criterion for placing immaterial goods in the market. An idea's value increases with the number of people who become aware of it and accept 
it as valuable. Therefore, the idea has to be compelling, affect the emotions of the recipients, and be communicated in an efficient way. Only as such can a symbolic value-added be generated. This complex system of distribution is often out of reach of the individual creative knowledge worker (even though new forms of web-based distribution are helping to reduce this problem).

Furthermore, attention is differentiated according to its origin: who gives attention to an idea? This is particularly important in creative industries in which reputational systems are crucial to quality management in the whole sector. Peers are competitors, but they can also provide the reputation and attention that can push forward the creations of an individual creative knowledge worker. For example, you might think of a researcher in humanities who needs other researchers' acknowledgement. This acknowledgement raises their scientific value and helps to improve their fund-raising capacity for research projects. The same accounts for an architect who needs the attention of and a reputation within the architecture community in order to improve their market value.

\subsubsection{Project Based Work and Irregular Time Schedules}

'Creative people always have experienced and even cultivated a blurring of time. Writers, artists, musicians, scientists and inventors often have erratic and irregular schedules, working from home and seemingly playing at work' (Florida, 2002: 14). The observation that Florida has pointed out above also applies to the periodic rhythm of creative knowledge work which is characterised by very busy periods and longhour working on the one hand, while then having periods without work on the other hand. This irregularity is caused by the organization of work in temporally limited projects. Working in creative industries means a continuous sequence of output-oriented projects that dominate the creative worker's lifetime. Sennett (2006) interprets this development as a new temporal pattern of life characterised by a dominance of periodicity.

This includes that in creative industries the formerly neat borders between private life and professional life become blurred (von Streit, 2010). With flexible work schedules, creative knowledge workers have the freedom to work whenever they want, not being bound to the 9-5 office hours that are typical in bureaucratic hierarchies in industrial companies. The other side of the coin is that creative knowledge workers also have to work long hours when the project has to meet strict deadlines. In this way, working at home, in the evening hours or at the weekend becomes a latent imperative in creative industries, causing trouble in family life and private spheres. In addition, there is much insecurity about the future situation as projects provide employment only for a limited time. Thus, the work-life balance in creative industries is a bi-fold story of deliverance from traditionally rigid work organization, but also of the emergence of new constraints (cf. Brown et al., 2010). 


\subsubsection{Emotional Involvement and Affective Work}

Hesmondhalgh \& Baker (2008) point to another problem of creative industries work: the emotional character of work. On the basis of interviews with production workers at a talent TV show in the UK, they found that the common argument of affective labour, which says that the creative autonomy pays off for the loss of security, could not be supported. Whereas it might be true that there is more creative freedom, this freedom translated into a 'pressure to be creative' among the workers in the studied production teams. In addition, the special segment of TV shows continuously produces emotions (among spectators, among candidates, among families of candidates). In this sense 'emotional labour' becomes 'over-emotionalised'. In addition to their own creative emotions, the freelance workers have to handle the emotions of all these other groups being involved in the production. This leads to negative emotionality among the workers: stress, exhaustion, depression, and conflicts with the candidates, the candidates' families, and the spectators.

Furthermore, there is strong competition integrated into the production system. Production workers compete to find the best candidates to push forward the TV show. This leads to negative emotions between the workers in the team. Therefore, Hesmondhalgh \& Baker (2008: 115) conclude: 'Our view is that autonomist concepts of 'immaterial labour', 'affective labor' and 'precarity' are at best evocative metaphors rather than theoretical-political constructs with any analytical force.' They opt for a more careful definition and more adequate theorization of the 'affective labour' concept in specific cultural environments in order to better understand these precarious situations. Also Gill \& Pratt (2008: 17) point out that there is an important 'role played by affect in generating consent (or even passion) for working lives that, without this emotional and symbolic sheen, might appear arduous, tiring and exploitative'. So, the emotional involvement into creative knowledge work is connected to professional identities in a positive and negative way. The positive effect of this emotional identification is that the workers gain intrinsic motivation from their work. On the downside, this delivers a good argument for keeping pay and labour market regulation on a low level. Thus, the emotionality of creative knowledge work also exposes workers to the risk of exploitation by commissioning clients and employers.

\subsubsection{High Skills vs. Low Pay}

Betzelt (2006) presented a study on the work life of the 'flexible Wissensarbeiter' (flexible knowledge worker). She found these workers to represent a proper type of income earners (Erwerbstyp). Her 'flexible knowledge workers' were characterised by contingent work, low income, and a disappearance of gender bias in the sector. Yet, her workers showed high professional skill levels and were highly educated, and they developed individual strategies to deal with their precarity in absence of public regu- 
lation and social protection. A subjectively coherent understanding of the proper profession (subjektiv-kohärentes Berufsverständnis) is very important in managing such risk on an individual basis. The individual workers make sense of and bring meaning to what they do. This construction of sense and a professional self-understanding represents a specific collective risk management system that allows individual creative knowledge workers to face the internalised market risks and the commodification of creative knowledge work.

Risk management in knowledge sectors is organised in ways very different from traditional Fordist unions, because creative knowledge workers are rather individualised (Betztelt, 2006). Collective action tends to be temporarily and based on networks. The support systems offer services in the field of business development, marketing, and vocational training for the individual workers. A high demand seems to exist in business knowledge, which is insufficiently taught in humanities from which many of Betzelt's knowledge workers start into the labour market. Yet, this collective organization is still rather inefficient and underdeveloped, having no real power to protect individual workers against market risks.

Furthermore, Betzelt (2006: 67) points out that precarity is not equally distributed within the knowledge sector: 'Based on intrinsic motivation and a reflexive professional understanding, highly skilled freelancers develop active-reflexive strategies to face the risky conditions, which lead to different, but not necessarily precarious, modes of social inclusion.' Creative knowledge sectors, according to her, are characterised by profiting at both the producers' and the consumers' side from the low income levels of the workers. Thus, she doubts that the current financial organization of these sectors is sustainable for its workforce. From a German perspective, she argues for better social protection in the sector (especially in terms of health insurance, unemployment, and pensions) as she has observed that the ability for individual protection is too weak.

Also, sufficient social protection schemes could work as a motivating factor to enter into freelancing/self-employment, which in general must not be precarious if protected. Betzelt (2006) considers low regulation in creative knowledge sectors as a general problem throughout all countries (to be thought of as a convergence of working conditions), she also sees specific national potentials for installing social protection (divergence of working conditions). First attempts are visible in German social protection to open traditional institutions for the new flexible workers. Finally, she argues for a reform of national income statistics. Here, a better registration of freelance income and an improved combination of income and household structure patterns are necessary. The actual situation of freelance creative knowledge workers can only be monitored and social security schemes can only be fine-tuned to their needs if such monitoring data is available.

Similarly, Manske (2007) studied the life of freelancing IT workers in Germany, titling her study Präkarisierung auf hohem Niveau (precarization at a high level). She conceptualises creative industries as radicalised markets in which risk is delegated to the individual freelance worker. Interviewing web designers, she found them to feel 
left alone with their insecurities by the government and large enterprises. In a distinction between material and institutional-legal dimensions of insecurity, Manske (2007: 216) mentions the double character of their exclusion: 'The income situation of web designers is insofar precarious as they obviously fit neither into the standards of traditional freelance professions [in Germany: lawyers, medical practitioners, architects, etc. with high income and private protection] nor the dependent labor force [lower income but public social protection].' In line with Betzelt (2006), she stresses the subjective professional understanding that results from this mismatch of material and institutional-legal resources on the one hand, and the market realities of the web designers on the other hand. Manske also points out that individual strategies are developed to face the insecurities, which she calls 'eigenverantwortliche Teilhabeprojekte' (selfdependent participation projects). These strategies are composed of self-dependence as well as pronounced future optimism, which leads to the conviction that things could be changed. She concludes that precarity is conceived of as self-determined among the web designers of her sample. They strongly stressed autonomy and creative freedom. Manske (2007) also mentions that this understanding of one's own precarious situation ('aktive Gestaltung prekärer Lage'-active figuration of precarious situation) is only possible because of the high cultural capital of the web designers.

This therefore brings us to a new dilemma in creative knowledge sectors: the workforce is highly skilled in terms of professional education, and often highly talented and motivated, yet the pay for the delivered work is frequently below average (cf. Brown et al., 2010). A personal investment into skills and education will not necessarily be rewarded anymore by an above average income.

\subsubsection{Missing Regulation and Liberal Labour Markets}

Connected to what we have seen above, Lange \& Mieg (2008) consider creative industries as emerging markets that have to be understood as being in the process of constitution. There do not yet exist efficient regulation schemes as in the established industries (e.g. trade unions, industrial organizations, wage agreements, etc.). The authors argue that the adaptation of established regulative institutions might even be an obstacle to receiving attention as an economic force. The emerging creative industries are only perceived as something 'new' if differences in the organization of production can be expressed. Thus, structural insecurity is inherent in the creative industries. There is no traditional scheme for fixing prices, for organizing the market relations, or for general evaluations and the legitimization of someone/something inside of this market. Lange \& Mieg (2008) consequently identify creative industries as being incompatible with traditional modes of regulation. They suggest conceptualizing creative industries as a 'market-as-network', in which the market is regulated in totally new ways by networked reputation, meanings, values, prices, and thus security within a liberalised and deregulated environment. So regulation and self- 
organization might be less sophisticated and individual market participants are thus more exposed to risk while having less power to negotiate sufficient income to cope with this risk. They have to rely even more on personal networks as a back-up against insecurities.

This fact of missing labour market regulation also means relief from Fordist control mechanisms (rigid structures, hierarchy, financial incentive systems, and bureaucracy). There is a new type of 'soft control' (Florida, 2002: 13) that unchains creative knowledge workers from these traditional control mechanisms as known from manufacturing or low-end services. In addition to hard financial aspects of work, creative knowledge workers are motivated through intrinsic motivation (more in detail see below section 2.3.8). This means they appreciate the freedom of selfmanagement. They can structure their own schedules and are responsible only for the delivery of an output, but it is up to them how they structure their work. Through peer recognition and reputation they also use their work for the creation of their own professional identity, which is not related so much to a company or employer but to the wider field of peer colleagues (cf. Florida, 2002).

On the other hand this freedom also means that creative knowledge workers often have to bear many of the market risks. As far as demand in the market exceeds supply, everything is good for creative knowledge workers. But if creative markets have a surplus of labour, the risk of participating in this market increases for individual creative workers. The individual option is then to avoid market participation through exit strategies, or to diversify risk through holding multiple jobs within creative industries or across different labour market sectors.

\subsubsection{Multiple Job Holding}

Multiple job holding is a common practice in creative industries. This is often driven by mere economic necessity. I mentioned earlier that creative industries are characterised by the 'winner-takes-all' mechanisms (cf. Caves, 2000). There are very few 'stars' who earn a lot, but there is a large majority of creative knowledge workers who 'starve' in the literary sense. The latter often have to take second jobs in different professional fields to earn their living.

This multiple job holding also has another functional character, as Florida (2002: 13) mentions: 'Today, the people in my interviews identify themselves through a tangle of connections to myriad creative activities. One person may be simultaneously a writer, researcher, consultant, cyclist, rock climber, electronic/world music/acid jazz lover, amateur gourmet cook, wine enthusiast or micro-brewer. The people in my interviews report that they have little trouble integrating such multiple interests and personae. This kind of synthesis is integral to establishing a unique creative identity.' Thus, having multiple jobs becomes normal and is essential for people to mark their individual identity. The individual curriculum vitae is continuously under construc- 
tion. It has to express individuality and distinction from others through a unique combination of professional experiences and backgrounds. Here, multiple job holding becomes redefined as a positive property of the individual career. This observation points out a central difference to traditional industrial careers in which a clear linearity without interruptions was considered an indicator of success.

European Labour Force Survey data suggests that around 6\% of people in creative occupations hold several jobs as compared to $4 \%$ in non-creative occupations. In particular, the writers and creative or performing artists (10\%), artistic, entertainment \& sports associate professionals and fashion professionals (9\%), social scientists (8\%) and health professionals (8\%) are affected by this phenomenon (European Commission, 2010b: 203).

\subsubsection{The Role of Intrinsic Motivation}

In psychology there is a difference between intrinsic and extrinsic motivation in relation to the work in which one is engaged. Intrinsic motivation is nurtured by selfexpression, freedom of organization over one's work, self-esteem, self-realization, and the pursuit of one's own goals rather than that of others. By contrast, extrinsic motivation is related to financial rewards, the amount of paid vacation, job security etc. Florida (2002) remarks that in creative industries the intrinsic motivation is often more important than the extrinsic motivation. He identifies three main values that characterise the creative class. First, creative knowledge workers are strongly orientated towards distinguishing themselves from the mainstream. They avoid conforming to traditional or modern values and they resist group-oriented norms. Ironically, this leads to individuality and non-conformity becoming the new mainstream. Second, creative knowledge workers are orientated towards meritocracy. This means they have a strong work ethic. They set goals for themselves which they seriously try to achieve. Thus self-esteem and achievement are central values for this group. Also one's reputation in the professional peer group is a significant issue and makes creative knowledge workers very attentive to the feedback they receive from their colleagues. This goes along with a diminished importance of material and financial status. What you have is not as important as what you know and what you do. Work has to make sense and be in line with one's individual value system. Third, creative knowledge workers are driven towards environments that signal diversity and openness. Given their individuality and non-conformity they need places where they can feel accepted in their 'otherness'. Also, difference is an important input factor for work, stimulating the exchange of different values, convictions and ideas (Florida, 2002: 77-80). Florida cites studies by political scientist Ronald Inglehart (2000) as well as sociologists Ray \& Anderson (2000), who have looked at changing value systems and norms in the postindustrial societies. In particular, the group of people who are neither traditional nor modern form an emerging segment of society. They tend to be orientated towards pro- 
gressive values. They engage in activities that benefit the wider community. They also do not understand themselves as orientated to material values, a fact that prompts Inglehart to speak of creative knowledge workers as a 'post-materialistic' group. Here, Florida (2002) remarks that this shift in norms and values is based on material security. Our post-industrial society could allow post-materialism as industrial times have brought us material security. This means that current orientation to 'quality of life values' could be read as a post-scarcity effect or a reversal of the protestant ethic (cf. Florida, 2002: 81f.).

All of these aspects make creative knowledge workers vulnerable to market exploitation. They often underestimate that material security is not granted in the post-industrial society, but they still have to shelter their own material security by doing business. In the end, they have to make money with their creativity. As mentioned earlier, creativity is difficult to price, and creative knowledge workers themselves often have less interest in developing a price mechanism than their market counterparts, capitalist businesses, who would buy their products and services. Making money seems to contradict the post-material and meritocratic values of the creative class. In consequence, creative knowledge workers are vulnerable to power asymmetries in the markets.

\subsubsection{Gender Aspects and the Compatibility of Family and Work Life}

Gender issues are poorly studied in relation to the creative industries. Yet, what research there is has produced interesting results. Looking at cohabiting couples with children, Henninger \& Gottschall (2007) found that traditional gender arrangements (with a male bread-winner) are a prevailing pattern of the IT sector, whereas reversed gender arrangements (female bread-winner) were mixing with traditional models in other creative industries. Nonetheless, they found that women still suffer the pressure of responsibility for the household and childcare in both gender arrangements, making a combination of job and household more difficult for them. New forms of household arrangement therefore do not necessarily result in the equal participation of women in labour markets, although reformed labour regulation might foster this.

Studying job satisfaction of nearly 2,800 creative knowledge workers in the European Union, I also found that male workers are more satisfied with their work in creative industries than female workers (Nadler, 2010). However, both female and male creative knowledge workers in my study were more satisfied with their work environment when they had children. Thus, I suggest that there is mixed evidence about the social outcome of creative industries work. In contrast to my initial expectation that creative industries might have an experimental character for defining gender-based roles in a new way, I found persistant dissatisfaction for women. On the other hand, the flexible work schedule led to higher satisfaction for parents compared to those creative knowledge workers without children. 
However, Florida (2002) argues that creative production is not completely compatible with family life and tight social relations. Using the example of historic geniuses, he describes how they often had a large group of acquaintances and friends, but they were neither married, nor did they have children. As psychiatrist Anthony Storr (1988: 103; cited in Florida 2002: 34) said: 'If intense periods of concentration over long periods are required to attain fundamental insights, the family man is at a disadvantage. [...] If Newton had been subject to the demands of a wife for companionship or interrupted by the patter of tiny feet, it would certainly have been less easy for him.'

We can therefore observe that there is no straightforward development of a more family-friendly creative knowledge labour market in which gender equality is automatically implemented. Further studies are necessary to derive a deeper understanding of the social implications that the proliferation of flexible creative knowledge work in less regulated liberal labour markets will bring along.

\subsubsection{Synthesis: Creative Knowledge Work in Dilemma}

The character of creative knowledge production leads to different dilemmas for the workforce. First, the products and services are more immaterial, need more symbolic content, yet rely on widespread distribution and attention. They are thus exposed to the threat of plagiarism. The efficient protection of the creative product and its commercial exploitation become very difficult.

Second, creative knowledge work is linked to being part of the creative knowledge worker's life. Termed 'bohemian' by Florida (2002), these sectors' work provides its workforce with a non-monetary gain in identification opportunities - with a certain lifestyle or an aura of artistic and social avant-garde. Thus, the creative workforce is more exposed to the risk of exploitation by market forces (commissioning clients, supervisors in the company, etc.) than other sectors' workforces. In addition, this exploitation is often neglected or not even perceived by creative knowledge workers, who often emphasise the positive features of their work life. A good example of this different perception of creative knowledge work is provided by the opposing interpretations of creative knowledge workers like Friebe \& Lobo (2006) and by sociologist Bröckling (2007). While the former argue in their book 'Wir nennen es Arbeit' (we call it work) that creative knowledge work is a deliverance from industrial rigidity, the latter calls his book 'Das unternehmerische Selbst' (the entrepreneurial self) in which he argues that creative knowledge work brings along the constraint of continuous work without interruption at the costs of sacrificing private life. Bröckling calls creative knowledge work a type of self-exploitation.

Third, the creative industries are emerging markets. The character of being 'new' relates to a lack of labour market regulation and inclusive social protection. For now, it could be concluded with the words of Hesmondhalgh \& Baker (2008: 103): 'Cultural workers might be thought of as the pampered children of the bourgeoisie, and they 
may be relatively privileged compared with other kinds of worker, but the human costs of their working conditions are real enough.' Here, the authors refer to the fact that creative knowledge workers often celebrate themselves and their liberal work environments, yet they seem to underestimate the economic, social and psychological long-term consequences of such a lifestyle.

Theoretically, creative knowledge workers should be very dissatisfied with the security and monetary aspects of work, but actually they report high satisfaction with the aspect of emotional and affective work in a liberal environment. I call this the 'trade-off hypothesis': within the satisfaction of creative knowledge workers there is a trade-off between 'hard factors' (pay, job security, contract forms, etc.) and 'soft factors' (self-actualization, freedom, stimulating aspect of work, challenging atmosphere, symbolic production, identification, etc.). Their decreasing satisfaction with 'hard factors' might be compensated by a growing satisfaction with the 'soft factors'.

Brown et al. (2010), in trying to test this 'trade-off hypothesis' using the cases of creative knowledge workers in Birmingham (UK), Leipzig (Germany) and Poznan (Poland), have found hard factor settings of creative knowledge work to be disadvantageous compared to general labour markets: creative professionals had to work above average hours; they frequently had below average income despite being highly-educated; they were more strongly affected by temporary employment. These negative hard factor settings also translated into feelings of job insecurity and precariousness. Nonetheless, these feelings are compensated by positive perceptions of the creative knowledge work environment. Having influence over one's own work, a sense of achievement and intellectual challenges were considered main motivators for ongoing professional engagement in the creative sector. Brown et al.'s findings (2010) suggest a partial verification of the 'trade-off hypothesis', but it is still unclear to what degree this affects the social sustainability of creative industries' employment.

So far, it is difficult to know if creative knowledge sectors really develop towards an avant-garde labour market in a wider social sense and not only from a discursive and hedonistic perspective. There remain several questions about the social sustainability of creative knowledge work. Suspicion remains that the over-estimation of intrinsic job aspects leads to the exploitation of individualised creative knowledge workers. Further research is needed to clarify if there is any effect of casual and individualised creative knowledge work on general life orientations and social patterns of creative knowledge workers (e.g. stability of partnerships, family formation behaviour, solidarity with other social groups, etc.).

There is also reason for positive conclusions: work environments in creative industries have a delivering momentum as they allow for new forms of self-organization. As several scholars have pointed out, local networks and milieus represent flexible means of social security. However, the modes of security provision are not comparable to traditional industrial sectors. While in the latter security was provided through formal regulation (e.g. collective labour agreements, unions etc.), in the 
former it is provided through internal quality management, reputation and trust that establish security against market risks.

\subsection{The Creative Knowledge Worker between Arts and Science: My Own Definition}

As we have witnessed so far, defining the creative industries as well as the creative knowledge worker is not an easy task. There are different opinions about their attributes, and there is much discussion about the best definitions thereof. So far no generally convincing solution has come up. Most studies and research projects that deal with creative industries use their own definitions. This means I will do so for my research, too.

So far, I have used the notion of the 'creative knowledge worker' without reflecting on its specific meaning. I will now pick up on that. First, I was attracted to simply using the term 'creative class' as used by Richard Florida, but he has been criticised a great deal for using that term. I also agree with some of the criticism, but I quite liked the openness and inclusiveness of Florida's definition. It counters the exclusiveness of some European definitions (cf. UK DCMS, 1998; European Commission, 2010a; European Commission, 2010b). I also liked the idea of basing definitions on the actual occupation of workers instead of industrial classifications of employing companies. Occupation indicates if a person is working in a creative job regardless of which economic sector their employer is registered with. However, what I dislike about the notion of 'class' are its sociological implications. Even though Florida tried to distance his understanding of 'class' from common sociological understandings in the tradition of Marx, he still assumes a strong homogeneity of a social group that, according to my conviction, is quite heterogeneous. After years of research in creative industries, I do not think that there is a class consciousness amongst the main actors of creative industries. This might change in the future, if political and scientific discussion about creative industries continues and a broad public as well as the creative knowledge workers themselves internalise a positive connotation of the term 'creative class'. Nonetheless, I would point out that this group of people is very heterogeneous and also pursues the goal of individualization and distinction. Being a good artist or a good scientist means being different from others, standing out from the masses. Instead of a unified class, I prefer to speak of individual 'creative knowledge workers', who are each a case in themselves.

Why do I speak of 'creative knowledge' workers instead of only 'creative' workers? Why do I put the two components 'creative' \& 'knowledge' into my term? I understand the adjective 'creative', and the related noun 'creativity' in the sense of artistic expression (cf. Bröckling's first field of creativity; see section 2.1.4). Second, I use the word 'knowledge' as related to the idea of a more explicit and abstract scientific form of knowledge that can be distinguished from everyday practical or implicit knowledge. 
Thus, knowledge is something that is only produced by a specific group of professionals. Not limiting both these terms here would cause a 'catch-all' problem. The limitations at this point have an epistemological function; I want to be able to identify a study group from which to sample for the empirical study later on. It does not mean that I think this is the only way to define these two terms. I am aware of and I support other definitions in other contexts.

The introduction of the two components 'creative' and 'knowledge' has two consequences. First and most obvious, I merge the two into one term. Thus, I suggest belonging and similarity. I include a large variety of occupations that at a first glance might differ substantially (e.g. the scientist from the painter), but I think that both related professional fields still share certain characteristics of work life. To me, there is a continuum between a mere knowledge worker and a mere creative artist. So let's take both, a scientist and an artist, as illustrative theoretical figures that represent the extreme of an axis on which most of the empirical reality might be found. Most creative knowledge workers will be positioned somewhere in between, working in multiple jobs, doing projects at the intersection of arts and science. They share certain features and they can be distinguished from professional groups in other economic sectors. I hope I made clear how work life in creative industries is currently described in the literature (see above section $2.2 \& 2.3$ ), but I will repeat it briefly in the light of the theoretrical figures of the 'artist' as a creative worker, the 'scientist' as a knowledge worker, and the empirical continuum between these two:

- The market is organised in small and independent units. Often these units only consist of freelancing self-employed individuals who flexibly gather into problem-oriented teams, bringing in their specialised skills. Artists often work as freelance workers with a strong focus on individualistic perspective, but they also form groups to realise larger art works. Scientists are still employed by institutions, but the work within institutions becomes more and more segmented into smaller units, which are problem-oriented as well. The individual scientist can also pursue their very individualistic research projects, just like an artist.

- The work is temporally structured into small, short-term projects that succeed each other, sometimes with and at other times without interruptions and breaks in employment. Both scientists and artists are contracted based on project runtimes. When a given project ends and there is no immediate follow-up project, both will face periods without stable income, and will be dependent on social security. The composition of project teams also follows this periodic logic. The team's composition is continuously subject to change with the succession of projects. This calls for specific social skills, such as the capacity to adapt to new colleagues' characters and overlook interpersonal differences. The common goal is the joint project elaboration and not to become best friends. Yet, having no stable colleagues anymore, workers are forced to develop more superficial and hastily constructed social relations that are functional in economic terms and also provide a 'friendly and fun' social environment. 
- $\quad$ The workforce is highly educated and has a high affinity to life-long learning. Both artists (at arts colleges) as well as scientists study and undergo additional professional training during their post-graduate time. Whereas there may be a lot of affective and emotional aspects of working in these fields, there is also a lot of explicit knowledge that has to be incorporated in order to be successful in the labour market. Knowledge gathered through higher education is an important productive factor in these fields of 'brain work'.

- The revenues and profits are redistributed in asymmetrical ways, with a small group of stars earning a lot, and a large majority of workers with low income levels. Thus, for most of the workers it means that the modern logic of returnon-investment in the field of education does not work anymore. This observation accounts for both an artist who has not become Andy Warhol or Damien Hirst as well as for a scientist who has not become famous outside his or her specific academic field. In academia there are also examples of individual scientists who have become 'world stars' and make a lot of money with presentations, expertise, or from copyrights on publications (remember e.g. Richard Florida and the Creative Class Group).

- The work is mainly immaterial and non-manual, namely 'brain work'. A lot of work is related to producing ideas, concepts, strategies, knowledge, problem solutions, emotions or symbolic meaning. This implies that production can be organised in a more flexible way; oftentimes a computer and internet access is sufficient for production. Thus, flexible work hours and home office models have become part of scientific work, and thus approach the flexible working hours of artists. Also a certain spatial flexibility accompanies both science and arts. If it is using work steps where a computer and the Internet are the main resources, a lot of work can be done independently of place.

- Within the markets, access to distribution channels is controlled by single powerful gatekeepers. Thus, profit margins are not only in the hands of individual workers. This accounts equally for an artist who needs a high-rank gallery to make money with their artwork as for a scientist who needs renowned journals and publishers to distribute his or her scientific findings. The value of a scientist is measured according to publications in international journals and their position in citation indices, which are based on these publications. The problem then is that there are individual journals which are read more than others, and their editorial boards have power in terms of accepting people for publication or not. Finally, being published and cited increases the market value of a scientist, particularly in terms of having a higher probability to receive funding for their research.

- Creative knowledge work has a character of self-organisation in the frame of minimal institutional structures. The worker is self-dependent and autonomous: they have to construct and build their own career. There are no clear career paths provided as an orientation structure by employers or the market. Whereas for artists there have never been such pre-defined career paths, they are also beco- 
ming less structured in science. Tenure track appointments are not the rule anymore. Ways of accessing chairs for professorship have been multiplied (for example, through the introduction of so-called 'junior professor' positions in Germany). Work contracts have also become more flexible and short-term, forcing scientists into the logic of project rhythms.

- Individual workers continuously compete with each other for resources. In both sciences and arts, scholarships and grants play an important role for individual career advancement. In addition, competition becomes evident in the search for funding for larger projects through foundations or private companies. The more market-oriented arts and sciences are as competitive as any other economic sectors. Yet, the specific character of artistic and scientific worlds - with small specialised units that are flexibly put together in short-term projects - causes a continuous alternation between competition and collaboration. Individual actors might have competed for resources yesterday, they work together on a team today, and they are unsure what their social relation will be tomorrow. There is less stability and clarity of social relations and roles.

- Workers are highly motivated by intrinsic aspects: self-actualisation, personal curiosity as well as satisfaction drawn from work come along with an intersection of professional interest with private interest ('work as hobby'). Thus, these individuals dedicate a lot of time to work, as work often has a connotation of 'passion'. Working in these sectors is often far from being a simple bread \& butter job which only serves to earn an income to finance other spheres of a mere private lifeworld or hobby, and in which completely different interests exist. For artists and scientists their work is often linked to a personal interest that cannot be distinguished from private life.

- Pricing often does not follow traditional market models. For example, works of art are not sold as a mass product with small profit margins and economies of scale. During production it is often unclear what price the final output will achieve because artwork has to be sensually experienced, causing an emotion in a potential buyer. Artwork is sold in unique pieces or small series and then draws value from attention to it and from discursive elements (e.g. how an expert or a broader public speaks about it). The same discursive elements also come into play when scientists publish their scientific outputs. It is very difficult to anticipate the return-on-investment that financing a scientific project might generate in the future in terms of public attention.

Given these shared aspects of the character of creative knowledge work, I believe that we can think of scientists, artists and of all people in between as one group, yet within the limits that we focus on similarities between individual professional situations.

Second, by using 'creative' and 'knowledge', I also suggest difference. I refuse neither one nor the other-both words have a more or less equal semantic power. However, I believe that there are underlying differences in being occupied as a scien- 
tist, who to me is the prototype of a knowledge worker, producing scientific, abstract and explicit forms of knowledge; and an artist, who is prototypical for a liberal and autonomous creative figure.

Then, there is also a methodological problem that I see: my research project is an exploratory one that will study in detail a small number of individual cases. Thus, I do not study a large group through quantitative data generation (e.g. a quantitative standardised survey) or secondary analysis of existing statistical databases. I conduct qualitative interviewing. I think that for statistical analysis and for quantifying creative industries it is essential to be selective and define precisely. Otherwise, data sets become unnecessarily complex and would not be manageable anymore. Yet, in doing a qualitative exploration of a very specific field-namely transnationally multilocal workers in creative industries-I do not think that it is helpful to exclude interesting cases of creative knowledge workers in an exhaustive way ex ante. Exploratory qualitative studies often struggle with the problem of field access and of identifying relevant cases. It becomes difficult to find interview partners in complex and sophisticated qualitative studies with too many and too rigid selection criteria. In exploratory studies, following the grounded theory principles, the problem arises from the question of finding relevant cases. Thus, the definition of a target population should not be too rigid.

To sum up, as creative knowledge workers I understand those people who are included in the broader definitions of creative industries, including scientific occupations, non-profit cultural activities, craftsmanship and also business services. In the specific field of creative industries, multiple job holding is a common practice. Thus, constructing a definition too narrowly would likely be dysfunctional as it would not allow me to capture the professional hybridity of workers in the creative industries.

\subsection{Creative Industries and their Relation to Places}

In the literature on creative industries, the information society or the knowledge economy it is a repeated argument that these new forms of economic activity cluster mainly in selected urban agglomerations. At a first glance, this observation seems counter-intuitive, as ICT and the immaterial character of 'brain work' should allow workers to locate everywhere and independent of place, thus equally including rural and remote areas. Yet, there is logic behind this focus on urban agglomerations which is is based on the fact that creation and knowledge transfer are strongly linked to face-to-face interaction and communication between diverse people. Therefore, urban environments provide more advantageous locations as compared to sparsely populated areas. Peter Meusburger writes in the introduction to his book series Knowledge and Space (2008: 1), 'In the age of telecommunication, spatial disparities of knowledge have not become irrelevant. Quite the contrary, their significance has increased.' 
Creative knowledge workers, managers, and freelancers prefer to work and live in urban milieus, where they find a critical mass of other people for cooperation, inspiration, and networking in spatial proximity (see Lange, 2005). In addition, they find a large number of consumers and early adopters for their symbolic content in the big cities. Lately, creative knowledge workers have even been discussed as drivers of a process of re-urbanization or the renaissance of the core cities after a long period of suburbanization and urban sprawl (see Wiest \& Zischner, 2006; Wiest, 2008; Siedentop, 2008; Spellerberg \& Wilbert, 2008; Gornig \& Mundelius, 2012; Kujath, 2012). However, not all urban agglomerations attract the creative industries in the same way. 'Places have replaced companies as the key organizing units in our economy', says Florida (2002: 30). Here he refers to the fact that places such as urban agglomerations have certain location specific assets that either work in an attractive way or not. The main questions are then: how are creative industries linked to place and which features of places are important?

\subsubsection{Urban Diversity, Open-Mindedness and Tolerance}

Florida's books (2002; 2005; 2008) always rotate around the same line of argumentation: nowadays, creative industries are crucial for economic growth. Thus, for a place it is of utmost importance to attract and retain a certain stock of the 'creative class'. In Florida's view, a city is more attractive if it can provide a tolerant and openminded atmosphere. Creative knowledge workers look for inspiration based on difference and a place where they feel accepted in their individuality and non-conformity. Florida (2002) methodologically translates this tolerance into a 'gay index', a 'bohemian index', a 'melting pot index', and a 'racial integration index'. The first index measures the relative concentration of gay people and the second the relative concentration of people working as artists in a given place. The third index allows for measuring the concentration of foreign-born people. The fourth index is a measure of the degree of integration or separation of different racial groups who live in a certain location. Correlating these indices to data about economic growth, Florida found that the more concentrated foreigners and gays are, the more productive is a place. Florida was often criticised for talking about a causal relation between these variables, yet he actually does not say that there is one (Florida, 2002: xvii). His statement, however, includes an important finding: tolerant places are more likely to grow than intolerant places. He remarks (2002: $\mathrm{xx}$ ) that it is about '[...] habitats open to new people and ideas, where people network easily and offbeat ideas are not stifled but are turned into new projects, companies and growth. Regions and nations that have such ecosystems are likely to do the best job of tapping the diverse creative talents of the most people, and thus gain competitive advantage.' Not astonishingly, Florida then explains that the creative class is more attracted to large urban agglomerations where diversity can be found - diversity in terms of the people living there, in terms of the ideas and 
lifestyles being accepted, or in terms of heterogeneous stimuli. These places allow creative knowledge workers to express themselves, to experiment and to develop their own identities.

Testing Florida's diversity hypothesis, the European Commission (2010b) found that there is no link between diversity in the EU, as measured in the share of foreignborn people, and the concentration of creative industries. In the EU, creative industries' concentration is strongly related to the population size of a place. 'It is obvious that size matters', says the European Commission (2010b: 213). Only the human capital, measured as the share of people holding a tertiary education degree, is correlated with creative industries.

D’Ovidio adds that large cities offer a larger opportunity for encounter and inspiration with other creative knowledge workers (2010: 133): 'High density implies close proximity and consequently a high potential for face-to-face interaction and building relationships of exchange, support and trust. [...] It is the diversity of creative workers, when these are highly packed into limited space, that facilitates creativity.'

Therefore, we can observe that creative industries are not equally spread across space. In fact, they tend to concentrate on very specific urban agglomerations in which the potential for exchange is high, and where open-mindedness allows for experimentation and creativity. This is not to say that creative industries cannot be found in rural areas (cf. Ermann, 2011).

\subsubsection{The Role of Third Places}

Creative industries, as with many other economic sectors, tend to cluster in urban agglomerations for their diversity and the input and stimulus that come along with that diversity. However, there is another reason why urban agglomerations attract the creative knowledge workers and their businesses. Creative knowledge workers profit from dense social interaction with other creative people and with clients. Businessrelevant communication and interaction in creative industries not only happens during the core working hours, but also during leisure time and in settings which are not directly related to the professional sphere. For example, evening events such as vernissages or parties are important sites for knowledge exchange, information flow and project planning (Currid, 2007; D’Ovidio, 2010).

A large part of this creative interaction takes place in a world in between the professional and the private spheres, also between public places/space and private space. Places with this character between private (the so-called first places) and professional/public (the second places) are discussed as 'third places' (Oldenbourg, 1999; Soja, 1996). These third places allow for a reflection about the subjective relation of the creative knowledge worker towards the broader public and the local environment. This reflection leads to creation and innovation. Therefore, the availability of 'third places' is crucial for creative industries to thrive. 
In the 20th century there was already a growing interest in the 'third places' concept. The starting point was the observation that there was a traditional dichotomy of 'first places' and 'second places'. First places are those places that relate to the private life (e.g. one's own home, a second home in a vacation destination, the grandparents' house etc.). 'Second places' are those ones that are linked to the professional sphere (e.g. the workplace, the office, professional conferences, locations of clients and customers). Oldenbourg (1999) introduced the concept of third places as an intersection between these two traditional socio-spatial environments of people. To describe what a third place is, Oldenbourg introduced the following criteria (1999: 41):

- First, third places have a neutral character, which means that people can come and go without directly being forced to do so. Frequenting these places includes certain voluntariness.

- Second, third places are defined by social equality. People meet independently of their social status. Social status does not matter within the third place, and access to the third place is not bound to social status.

- Third, these places are characterised by a pre-dominance of communication and conversation in a playful, relaxed and less serious atmosphere. They allow for liberty from professional and private roles.

- Fourth, third places, in addition to being accessible for everyone, are neutral in the sense that they provide the feeling of being welcome and accommodating to different social groups. These places allow for diversity.

- $\quad$ Fifth, the third places are characterised by a group of people who visit these places on a regular basis. Mainly these people define the atmosphere, styles, and habits, but these people are not exclusionary toward newcomers; rather, they invite new people and introduce them into the social fabric of the specific third place.

- Sixth, third places are designed simply but they are comfortable. They provide a cosy feeling and do not exclude individual groups through specific interior design or modes of conduct. Thus, the built environment is also inviting and inclusive.

- Seventh, the mood of people and the way that interaction takes place has a cheerful character. It is about hanging around with people and making jokes. People respect each other, and hostility and conflict are not part of the environment.

- Eighth, third places can enter into its visitors' emotional awareness. A third place becomes a type of 'home away from home' that has become part of one's own lifeworld.

Whereas Oldenbourg (1999), and later also Putnam (2000) used the idea of the third place in the frame of a declining sense of community in US American cities, there is also a variety of scholars who have re-discovered this concept for the explanation of the interrelation between creative industries and the cities where they are located. More or less obviously, creative industries scholars refer to the characteristics of third places. Kunzmann (2009: 43) e.g. underlines how important public space and public 
places are for the emerging creative industries: 'Even if a large share of cultural life occurs in private space, for attractive cities it is the public spaces that remain the most important places of cultural production and consumption. [They have] an important social function in Europe's future cities, as they are the sites where the oft-cited face-toface contacts take place. There, people find a stage; they see and can be seen without having to pay entrance fees. For creative businesses these public spaces are indispensable. They provide the urban decoration, which they need for development and attracting attention.'

The European Commission (2010b) also concluded that creative industries tend to locate in urban agglomerations. Calculating location quotients based on occupational data for the year 2008, a significant difference could be observed between urban and rural areas. In some EU metropolitan areas, location quotients even rose up to 2.0 or higher, whereas thinly populated areas reached an average of around 0.5 to 0.6 (European Commission, 2010b: 209-211). This concentration process is explained by the benefits resulting from agglomeration economies and clustering, e.g. specialised local labour markets and the available local human capital and tacit knowledge; the knowledge spillovers between creative industries' sub-sectors; the availability of specific collective resources and infrastructures; access to place-based project developments and networks; participation in collective learning; or even a supportive local government and appropriate policies. Given the aforementioned supply-chain linkages between creative industries' sub-sectors, businesses locate close to other potential business partners. For instance, new media companies often settle where traditional media and/or software companies are already located. Equally, advertising companies locate close to newspaper headquarters as well as radio and TV stations (cf. European Commission, 2010b).

Furthermore, long-term observations show that the spatial distribution remains relatively stable, suggesting a certain path dependency. The project-based and flexible nature of creative industries also makes it more efficient to be in the hot spots, as it keeps transaction costs for new projects affordable. Face-to-face contacts here play a crucial role in the building of trust and support networks, as well as in the information flow between business stakeholders. Uncertainty in creative industries is so high that direct and unmediated access to the market is crucial for the survival of a business (cf. European Commission, 2010b; European Commission, 2010c; Lange, 2007; Lange \& Bürkner, 2010). The availability of third places is thus a central issue

\footnotetext{
9 Translated by the author from the German text: 'Auch wenn ein Großteil kulturellen Lebens in privaten Räumen stattfindet, sind für attraktive Städte doch öffentliche Räume die wichtigsten Orte kultureller Produktion und Konsumption. [Sie haben] eine wichtige soziale Funktion in den europäischen Städten der Zukunft, da dort die oft beschworenen Face-to-Face-Kontake stattfinden. Dort finden Menschen eine Bühne, wo sie sehen und gesehen werden, ohne Eintritt zahlen zu müssen. Für Unternehmen der Kreativ- und Kulturwirtschaft sind solche öffentlichen Räume unverzichtbar. Sie geben ihnen den dekorativen städtischen Rahmen, den sie brauchen, um sich zu entfalten und um Aufmerksamkeit zu finden.'
} 
for creative industries. It is in these places that informal networks unfold their power in organizing the creative knowledge market. In these places creative knowledge workers meet during lunch and coffee breaks or during events and soirées. Businessrelevant information can be spread by meeting up 'accidentally', and new project ideas can be developed. Moreover, trust is established in regular face-to-face interaction in third places, defining the membership in local scenes and networks (Lange \& Ehrlich, 2008).

\subsubsection{The Creative City as a Policy Field}

Creative knowledge workers are not only influenced by a city; it is also suggested in the literature that creative knowledge workers and their businesses heavily influence the cities themselves. Accordingly, there has been a broad spectrum of policies aiming at the development of so-called 'creative cities' (Scott, 2006; Landry, 2001). A large number of city councils and mayors would like to make their city a 'creative city' to which the creative people are attracted, and which then should benefit from their presence. How does this work? Currid (2007) e.g. mentions that creative knowledge workers positively affect the 'urban vitality'. They engage in the cultural milieux of a city, offering cultural amenities and organizing a vivid cultural life that consequently also attracts those who work in other sectors and who want to consume culture as a 'quality-of-life' feature. In addition, tourists might also be attracted by a vivid cultural life. As such, the presence of creative knowledge workers can have positive outcomes for a city.

In particular, in the frame of brownfield redevelopment (the functional redefinition of formerly industrial production sites such as factories and warehouses), creative knowledge workers are considered a pioneer group that often enters into decaying neighbourhoods and uses the vacant buildings for their own purposes. Artists, architects, urban planners and craftsmen welcome the often spacious buildings and experiment with the attribution of new function and meanings to these industrial structures. Inhabitants from other more established and wealthy neighbourhoods or from outside these cities then become aware of the cultural diversity that is developing via the creative knowledge workers who redefine decayed neighbourhoods. These people first come to the creative sites and begin to consume the cultural offerings, and later on they start to invest in these neighbourhoods. They buy property and increase real estate prices. As a consequence, the rental prices increase and many creative knowledge workers cannot afford to live and work there anymore. A so-called gentrification process finally leads to the displacement of the former pioneer groups. The neighbourhoods become wealthier and the cultural scene changes from a production-based to consumption-based area (cf. Schäfer, 2010).

The consequence of this observation is that policies are tailored to make cities creative. As Currid resumes (2007: 455): 'Following this line of thinking, planners and 
economic developers now seek to provide the amenities, consumption opportunities, and quality of life and place that attract high-quality human capital.' For politicians, urban planners and business developers in particular, the emerging debate about creative industries and the related 'creative city' concept arrived at the perfect moment. After the crisis of the New Economy, a new post-industrial economic sector was needed on which development strategies could be based. Policy makers thus rapidly adopted creative city policies and tried to develop their local creative industries. Such a discursive focus on creative cities resulted in a rhetoric that had been criticised early on because it neglected the associated social costs for the wider urban community. Critics blame this approach for its potential to worsen the situation of the poor and powerless people in the urban social fabric (see Hansen et al., 2001). If creative knowledge workers induce gentrification processes, then a concentration of scarce public resources for these actors is aggravating the problems of segregation and polarization in the cities (Ponzini \& Rossi, 2010; Evans, 2009). Furthermore, Florida mentioned that a creative city cannot be planned from scratch (Florida, 2002: xxiii): 'Growing a creative ecosystem is an organic process. [...] The development of such environments cannot be planned from above. The key thing to understand is that the solution lies in the hands of each region - in the knowledge, intelligence and creative capabilities of its people.'

Thus, we can see how creative industries have reached broad public awareness that has caused massive political attention, too. Yet, political action is often not grounded in professional analysis of the local opportunities and threats that come along with the political focus on creative city development. The political interest in the creative city concept can be observed worldwide as creative industries are suspected to have positive impacts on regional growth, particularly in metropolitan areas (ESPON 2013 Programme Coordination Unit, 2011).

\subsubsection{Language, Culture and National Frameworks}

A central element of creative knowledge work is language and culture. In order to produce symbolic values and content, creative knowledge workers need language as a medium to get their message to other people and to produce cultural goods. This property implies problems for the internationalization of creative businesses. However, this is less analyzed in the study of creative industries. Most case studies on creative industries focus on individual locales and on specific cities or countries. In doing so, they neglect the role of migration and mobility between countries and places for the creative industries and for the cities.

Few scholars have dealt with the nexus of mobility and creative industries. One such study was the famous book Eurostars and Eurocities by Adrian Favell (2008), in which he studied the life trajectories of young European creative knowledge workers. He calls these young and mobile workers 'eurostars' as they move freely between dif- 
ferent national and regional cultural contexts without feeling uncomfortable. Despite this, he observes that this free movement takes place in a very complex European environment. Favell says (2008: 26): 'Even the most casual traveller around Europe quickly understands that the continent today remains a Babel of national distinctions, local customs, and regional peculiarities, which demand of any European an extra-ordinarily high level of nationally specific know-how and local knowledge to feel comfortable living and working outside their country of origin.'

In an earlier work he commented on Europe's cities as locales of a free labour market in a similar way: 'Eurocities remain distinctive, variable environments at the international level, and one has to compete with all the in-built advantages of the local bourgeoisie. Only in rare cases is there a critical mass of foreign residents, such that the structure of the city itself is changed.' (Favell, 2003: 422; cited in Pethe et al., 2010: 164)

Equally, Pethe et al. (2010) stress the importance of language as well as local and national contexts for the attraction of creative knowledge workers within the European Union. Factually there might be a free labour market by law, but there are still large obstacles when it comes to the everyday practice of cross-border mobility in Europe. 'The remaining differences between nation states, the incompatibility of pension schemes and social security systems and other hard factors and bureaucratic obstacles as well as soft factors still affect international labour migration.' (Pethe et al., 2010: 164). Studying the examples of Amsterdam, Barcelona, Dublin and Munich, the authors show that it is the degree of cosmopolitan 'look \& feel' of a city which determines how accessible they are for international creative knowledge workers. Dublin, for example, has attracted a lot of international immigration with an English-speaking and open-minded atmosphere, while Munich could become less international as English is less often spoken in everyday life and national immigration regulation and tax schemes are disadvantageous. Thus, Pethe et al. (2010) emphasise the importance of cultural difference (language proficiency in particular) for the international mobility of creative knowledge workers. They found that the influence of cultural difference is lessened by the internationality of a national/local economy. Particularly, international investment and international headquarters are attracting migrant workers from other countries and therefore induce cultural diversity and otherness in specific locales.

Pethe et al. (2010: 187) conclude that the EU labour market is not yet characterised by 'free movement': 'Although the EU as a supranational organization aims to reduce the national regulations and wants to level out the differences in the international migration and economic policy, the differences are still more pronounced when compared with the USA which consists of a unified national market.'

Furthermore, Pethe et al. explain that it is not only the national and local economic and political context that explains the attractiveness of migration. In creative industries there is a sector-specific importance of local professional networks that inhibits international mobility: 'If they move to other regions, they often lose those 
pivotal contacts. This limits their mobility.' (Pethe et al. 2010: 188) Finally, there are also problems with the recognition of foreign educational degrees in European countries. This is a disadvantage for the international mobility of creative knowledge workers, who are characterised by their high educational attainment.

\subsubsection{The Role of Geographic Proximity: Creative Industries and Local Networks}

As we have seen above, local context seems to matter in a pronounced way in creative industries, thereby making mobility an adventurous undertaking. Why is local context so important to creative industries? An interesting question discussed in this field is the role of geographic proximity in product development. Ganesan et al. (2005) e.g. studied the product development process in the US optics industry. While optics is not really at the core of creative industries, the article still provides a helpful discussion of the theoretical positions concerning the role of geographic proximity. Many marketing scholars in business administration understand new product development as an isolated process within one firm, but other disciplines such as economics and economic geography have focused on the involvement of different actors in networks and clusters. Within these local clusters information and different forms of knowledge are exchanged. First, explicit knowledge circulates through formal agreements. Second, there are interpersonal and more informal means of tacit knowledge exchange between individuals from different firms. A basic condition of both forms of market-relevant information is geographic proximity, which allows for face-to-face contact. This face-to-face conversation supports the development of interpersonal and inter-firm trust and reciprocity as well as enduring strong relational ties. Furthermore, the concept of agglomeration economies argues that geographic collocation allows firms to profit from externalities such as access to skilled labour, distribution channels, knowledge spillovers, and market institutions (e.g. research institutes, business associations, interest groups).

However, cluster studies reveal few insights about the way geographic proximity translates into new products. Ganesan et al. (2005) question the dominant understanding of a causal relation between geographic proximity, strong relational ties and tacit knowledge flows. Using their empirical study in the optics industry, they suggest that strong relational ties might also emerge despite geographic distance, namely through ICT mediation. In particular, they found that email communication was very important for building up relational ties as well as for product development. This means that geographic proximity is not the only condition that is necessary for product development. Furthermore, they demonstrate that 'technical knowledge' is as relevant to product development as informal tacit knowledge.

Ganesan et al. (2005) distinguish between two forms of knowledge: non-codified and codified knowledge. They suggest that non-codified knowledge is best transferred by face-to-face contact because this mode of communication allows for non-ver- 
bal communication and synchronous feedback mechanisms, thereby enriching the understanding and reception of this tacit knowledge. Codified knowledge, in contrast, might also be transferred through ICT-mediated ways. For this reason, codified knowledge is not so dependent on geographic proximity. Second, there are two types of content in business relevant knowledge: process- and product-related knowledge. Ganesan et al. (2005) think of product knowledge as less complex than process knowledge. Product knowledge is thought to circulate easily through ICT-mediated communication, while process knowledge transfer is bound to close relational ties and faceto-face contact. In general, Ganesan et al. suggest that close ties are more valuable for any knowledge transfer than lose ties. This means that relational thickness is more important than geographic proximity.

According to these authors, creativity is the first stage of product development and it is largely dependent on tacit, non-codified knowledge, and thus on face-to-face contacts. The second stage of product development, namely prototyping and market introduction, is based more on process knowledge, which itself is more efficiently transferred by face-to-face contacts.

As an empirical result, Ganesan et al. (2005: 55) formulate 'that (1) geographic proximity is related to face-to-face communication but is unrelated to relational ties, (2) relational ties moderate several linkages in the path between geographic proximity and new product development, (3) face-to-face communication is less effective than electronic communication as a means of knowledge acquisition, and (4) knowledge content has a greater effect on new product development than knowledge form.' Consequently, the authors argue for a relativised understanding of the role of geographic proximity. Whereas geographic proximity is beneficial to face-toface communication, it is not straightforwardly related to the strength of relational ties. Given that relational ties are more important for knowledge acquisition, the common theoretical assumption that geographic proximity is generally relevant is not shared by Ganesan et al. In other words, if geographic proximity matters, it matters because relational ties in geographic proximity are stronger than relational ties at a distance.

Ganesan et al. (2005) support the idea that tacit knowledge circulates more easily in geographic proximity because it is transferred by face-to-face communication. They identify more formal types of knowledge as business-relevant. This formal knowledge might be equally or even better transferred by email and other ICT mediated communication, independent of geographic proximity: 'Our findings suggest that e-mail and other means of electronic communication are more critical to new product development than is frequent face-to-face contact with external knowledge providers' (Ganesan et al. 2005: 56). According to these authors, other studies seem to support this argument. While face-to-face communication might allow for the transmission of nonverbal and atmospheric information, it can also be inefficient in terms of providing too much unnecessary information. E-mail and ICT-mediated communication is more concentrated on a specific topic, and thus can be more efficient in certain contexts: 
'The socially laden nature of face-to-face meetings can actually be counterproductive. In contrast, e-mail appears to help focus communication on the business at hand, thus resulting in more effective transfer of knowledge that is useful for new product development' (Ganesan et al., 2005: 56).

They conclude: 'There is no magic that stems automatically from being located near other firms or research institutions in the same industry. Instead, a firm must first develop strong relationships with key knowledge providers to gain access to knowledge, regardless of whether these organizations are near or far' (Ganesan et al., 2005: 56).

However, we have to consider that Ganesan et al. (2005) looked at the optics sector, which could be counted as creative industries if one followed a wider definition including all R\&D activities. But this assumption could also be contested by supporters of a more narrow definition of creative industries.

D’Ovidio (2010) focused on more obvious creative industry sectors: fashion, art, entertainment and design. According to her analysis, tacit knowledge transfer plays a crucial role in creative industries, and therefore face-to-face communication is very important. As such, geographic proximity makes a difference in creative industries. As d'Ovidio says (2010: 114), 'There is empirical evidence that face-to-face interaction remains a crucial means of communication for their highly skilled workers, despite the development of new communication technologies and the low cost of their use. The reliance on direct interaction, and the requirement of physical proximity that this entails, are part of the explanation of the clustering of these industries in cities and in specific quarters of cities.'

As in other industrial sectors, face-to-face communication is an important issue for the transport of tacit knowledge and for the establishment of interpersonal and inter-organizational trust. Nonetheless, why face-to-face communication is so important, especially in creative industries, must be clarified. D’Ovidio describes several functional aspects of face-to-face communication that are relevant here. First, creative industries deal with the production of cultural and symbolic goods and services. But cultural and symbolic content is perceived very subjectively. Therefore, finding at least a minimum of inter-subjective agreement during product development is important for the success of new products, and such inter-subjective understanding can only be generated through face-to-face discussion in various social contexts. Furthermore, d'Ovidio calls to mind what I have outlined above (section 2.2.1 \& 2.3.3): creative production takes place in small and flexible teams, bringing together specialists from very divergent backgrounds. In order to find a common and inter-disciplinary language for a specific project, face-to-face communication is also relevant because it allows for intensive debate about concepts and their shared understandings.

As such, d'Ovidio describes that local-scale face-to-face contact and the trust built up and being reproduced from it is relevant for the establishment of a local creative community. This local creative community develops its own social dynamic over time, including codes and value systems. New members might be accepted within this community through a socialization process, namely the internalization of these 
local codes and values. The new members have to share the local culture, habits, and judgements. Acquiring this local cultural capital allows individuals to belong to the local professional community. Additionally, these local creative communities monitor themselves in order to maintain the quality of their products and outputs. Thereby, reputation systems are established that observe each individual member of the community and their impact on the community itself. If an individual creative knowledge worker increases their personal 'reputational capital', they have easier access to relevant information and are invited to project collaboration more often: 'As in the cultural industries there are no formal credentials that can guarantee the creative qualities of a person, an individual's reputation, which derives from being recognised as belonging to the creative community, is of paramount importance' (d'Ovidio, 2010: 115).

Finally, local context and geographic proximity are relevant for the unplanned and spontaneous occurrence of situations that help creative inspiration. In particular, the interaction between different networks of the creative industries (e.g. the fashion industry and photography) is necessary for creative processes and the development of successful products.

Through her studies of the fashion industry of Milan and London, d'Ovidio found evidence for another functional aspect of geographic location that is not primarily related to geographic proximity between actors. Linking one's own business with a specific location might have symbolic value, too. Places themselves have identities and there exist images of them in other places. If these place-specific images are similar or complementary to the business' symbolic values, it might be helpful to emphasise geographic origin. In d'Ovidio's study, Milan-based companies use the glamorous image of the built environment in the city centre to sell their prêt- $\grave{a}$ porter fashion. By contrast, London-based fashion companies operate more in the field of street culture, for which London is also more renowned than Milan. Therefore, London's businesses are also located in the centre of the metropolitan area, but they are distributed throughout several quarters within it, each of which has its own individual image. D’Ovidio (2010: 121) says: 'It can be argued that through their location fashion houses establish a link between the aesthetic quality of the built environment and the sophistication and originality of their production'.

By talking to fashion designers in these two cities d'Ovidio found that geographic proximity allows designers to maintain networks and thus strong relational ties. In contrast to the study by Ganesan et al. (2005), fashion designers are more dependent on geographic co-presence to stay in the business, in particular in main centres of the industry: 'The work of fashion designers seems to be all about being engaged in making and maintaining relationships, which requires direct and frequent interaction and therefore co-location of actors. The main demand of their job is to be in the city, constantly reachable and permanently available to meeting people who are part of the fashion system or are engaged in the creative field' (d'Ovidio, 2010: 125). D'Ovidio thus considers fashion industry relationships a 'contact sport' that is defined by three different scales. First, there is the individual project team, which is mainly rooted in the 
local context. These project teams - e.g. designing a new fashion collection - meet up in design laboratories that are often located in fashionable urban neighbourhoods. Then these neighbourhoods and the wider city represent a second important scale, where market-relevant knowledge is exchanged between workers from the same field, but from different companies and project teams. Third, there is a scale of local interaction, which is not only linked to the particular profession of the worker, but also to the industrial sector as a whole. Here, industrial events such as fashion weeks, trade fairs, fashion label parties, and presentations of new collections are important events for meeting with other relevant people, socializing and networking. 'Participation in these events is a must because by being present designers affirm their belonging to the system. It is also during these events that they gain visibility and recognition by the media.' (d'Ovidio, 2010: 127) However, it is not only about individual events. Here, the so-called 'third places' become important. D'Ovidio found that her fashion designers have very precise mind maps of where their industry is located within their cities. This includes bars and cafés where fashion industry people hang out and sudden meetings can take place. All of these three levels of local face-to-face interaction are crucial for reproducing and reinforcing one's own position in the market.

Intersections with other creative industries' sectors are also organised on the local level through interaction in public space and third places within the creative neighbourhoods. D'Ovidio found that London-based fashion designers heavily relate to artists and seek geographic proximity by locating in the same neighbourhoods. This allows for strong interaction, and this strong interaction with other sectors' creative knowledge workers is crucial for inspiration. D'Ovidio emphasises that fashion designers do not talk about the creation process, e.g. discussing a draft model of a fashion piece, with each other. Rather they use other professionals such as architects, painters, photographers to collect feedback and ideas.

D’Ovidio concludes (2010: 132): 'As they need to be connected in order to function successfully in their profession, time and energy are constantly invested in networking, in seeing each other and being seen in the 'right' places and events.' These right places have the following character (d'Ovidio, 2010: 133): 'Particularly for the quarters established in the last two or three decades, high accessibility, high quality of the built environment, a certain social mix and alternative, bohemian atmosphere are the main characteristics of these places.'

Interestingly, d'Ovidio also found hints to the problems that are associated with the local disembeddedness of creative workers and firms. Traditional Milan-based fashion labels such as Prada or Trussardi are orientating to global markets and hire new and innovative fashion school graduates preferably in England and France instead of employing those who graduate from schools within the city itself. This induces a problem of segregation in the local fashion labour market, with young Italian fashion designers facing difficulties in entering the industry. The economically successful labels do not engage in the local market anymore, as their outreach has become global. This also means that the local innovation and creativity system lacks 
support from the large fashion houses. Such local problems translate into a negative global reception of the Milan fashion scene and the fashion weeks, which have become apparently less interesting, affecting the market place in total. 'Monopolized by the 'big names' and lacking new names and faces, the shows are of little interest from the point of view of creativity and originality' (d'Ovidio, 2010: 134).

We can therefore see that geographic proximity has an important influence on keeping contact with the particular creative sub-sectors' players. As creative knowledge work takes place in a rapidly changing network structure, it is crucial for the individual worker to be present in a local context (cf. Storper \& Venables, 2004). While ICT and the Internet allow for global connection, work-at-a-distance and the more focused exchange of explicit and formal market knowledge, geographic proximity ensures face-to-face communication, which translates into trust, reputation and knowledgeability about developments in the markets.

\subsection{Creative Industries and Mobility between Places}

Based on US American experience, Florida (2002: 79) suggests that mobility is important among creative knowledge workers: 'Creative Class people are mobile and tend to move around to different parts of the country; they may not be 'natives' of the place they live even if they are American-born. When they are sizing up a new company and community, acceptance of diversity and of gays in particular is a sign that reads "nonstandard people welcome here". Here, Florida underlines his main argument of a 'free-floating' creative class. Being active in different places seems to be a special character of these 'creatives'. The specificity stems from their way of moving through space and thereby constructing and symbolically defining their own spaces (see Florida, 2002; Lange, 2007), which could closely be related to the notion of glocalization (cf. Brenner, 1998). The volatility (in the sense of temporary organization and short product life cycles) of creative industries leads to specific practices of community, such as 'glocal' networking (bridging the local and the global scale) and multilocal acting as one answer to the need for flexibility and constant innovation (cf. Sennett, 2006).

On the one hand, workers in these creative industries need a certain local rootedness in order to be able to produce their creative services and products from within the networked security of a place and local community. The integration into local networks (being based on geographic proximity and tight relational ties) also offers access to tacit knowledge (see Lange, 2005; d'Ovidio, 2010). This tacit local knowledge is one of the essential economic resources of the creative industries. On the other hand, these creative knowledge workers are highly dependent on their integration into more abstract networks on a global scale (see Florida, 2002; Florida, 2008). These global networks are facilitated by ICT and modern high-speed transportation infrastructure. Being globally integrated offers another economic resource for the production of creative services and consumer goods. It provides the 'creative class' 
with information about upcoming trends, new ideas and applications elsewhere on the globe so that the risk of a local 'lock-in' can be reduced (Grabher, 1993). Kunzmann also identifies the need for internationalization in creative industries (2009: 39): 'Creative industries have strong local roots. Yet, similarly as other economic sectors, in times of nearly borderless internationalization actors in the cultural industries are forced to establish durable international networks. Even though they might be heavily dependent on specific locales, they cannot only rely on local and regional markets. This has several implications for individual mobility as well as [...] for strategies of external information and marketing. ${ }^{10}$

Yet, mobility seems to be less of an issue among creative knowledge workers in Europe than in the USA. Musterd \& Gritsai (2010), having studied 13 European cities, point out that Florida's assumption of a highly mobile creative class which is driven to culturally vivid and open-minded cities cannot be supported in the European context. First, this is due to cultural constraints between European countries. People have to learn languages, native people are less open-minded towards foreigners, and national and local contexts work in very specific and distinct ways. Furthermore, in the European context institutional constraints are very important as an explanation for the lower degree of mobility. Nationally and regionally different education and health systems, pension schemes, labour market legislation as well as bureaucratic issues around business start-ups all inhibit mobility (see also section 2.5.4; Pethe et al., 2010). Musterd \& Gritsai resume (2010: 38): 'Our evidence also established that key actors [in creative industries] are much less mobile than some of the literature, notably Florida (2006), would like us to believe. [...] Florida's model may work for single young professionals or bohemians looking for inspiration or a quick career and ready to take off at any moment if they see a better chance. But it does not seem to apply to families with children in a school age, when a perspective of another language and a novel cultural environment may become a serious obstacle. It may also not work for middle-aged couples, where one of the partners is professionally connected with a certain European area or where the adjustment to other pension rules would also be seriously considered.'

Martin-Brelot et al. (2010) also critically add that mobility in the European creative industries is strongly dependent on personal trajectories. This includes that people tend to move to places where they are already related to other people. Thus, places do not only attract creative knowledge workers with their soft pull factors, but also with the personal relations that a mobile creative knowledge worker has to a place. However, for some creative knowledge workers it is imperative that they are globally

10 Translated by the author from the German text: 'Kreativwirtschaft hat starke lokale Wurzeln. Doch in Zeiten fast grenzenloser Internationalisierung sind die Akteure der Kulturwirtschaft gezwungen, ebenso wie andere Industriezweige auch, sich dauerhaft international zu vernetzen. Bei aller Ortsgebundenheit können sie nicht nur auf lokale und regionale Märkte vertrauen. Dies hat vielfältige Implikationen für individuelle Mobilität sowie [...] für nach außen orientierte Informations- und Marketingstrategien.' 
integrated if they want to stay in the market. They cannot only rely on personal ties. These workers have to travel a lot between different workplaces, offices, meetings and events. Be it for individual career advancement or the international expansion of their businesses, these people are mobile across borders and engage in different national and local contexts (Pethe et al., 2010).

Another aspect of the creative industries is the export activity across borders. According to Andrews' export base theory (1953), regional and urban development is quite dependent on how well a city or region succeeds in exporting its own goods and bringing in money from elsewhere. Businesses must try to export goods and services, if their home markets are characterised by a high satisfaction level of consumer demand. In projecting this idea to creative industries certain natural problems show up. Creative businesses, with their strong dependency on cultural stimulus and the cultural context, are still focused on their national markets. Language, in particular, is a central tool producing and communicating ideas, concepts and information. Furthermore, humour, social values and norms are important frames and inputs to creative production. This implies that 'going international' is not as easy as in other economic sectors. In addition, creative industries produce more services than goods, and services in general are less tradable (European Commission, 2010b: 204). Thus, more research is needed on the topic of the 'internationality of creative markets', as the European Commission (2010b: 204) remarks: 'While a number of studies, policy documents in particular, point to the growing importance of trade in creative industry products, and the sound export performance of the creative industries, this issue has until now almost never been studied in a thorough way.' Looking at export figures, creative industries accounted for 3.3\% of total exports in the world in 2005. Yet, this share is slightly decreasing as other sectors' exports grow more rapidly than the volume traded by creative industries. Given the role of linguistic barriers, it is not astonishing that two thirds of global creative industries' exports relate to design activities that work mostly in a visual and non-verbal way. In second place, publishing services and goods were exported (13\% in 2005; cf. European Commission, 2010b).

There is also a geographic imbalance on the global scale. The European Commission's Competitiveness Report reveals that China, the US and the EU-27 account for $66 \%$ of global creative industries' exports (intra-regional exports not included) - with one third by China, a quarter by the EU-27, and the rest by the US (European Commission, 2010b). These three world regions also deliver different goods and services to the world market. The EU mainly supplies products in the fields of design, publishing and visual arts to other parts of the world. New media products are also playing an increasing role. Within the EU, mainly music and audiovisual products were traded across borders. China's creative exports are dominated by design products and services as well as arts and crafts products. Furthermore, China has a rapidly growing share in new media exports. Here, the European Commission (2010b: 205) mentions that 'these findings are quite intuitive and emphasise the role of common language and cultural norms in creative industries' trade. For instance, prevailing cultu- 
ral and linguistic differences between China and the Western hemisphere make it almost impossible for the Chinese publishing and music industries to compete in world trade'. By contrast, the US creative industries are competitive exporters of publishing, visual arts as well as new media products and services. Yet, US creative businesses underperform in exports in the design fields. Even though the exports are only growing slowly in creative industries, the growth is linked to a changing structure between these three world regions. Between 2000 and 2005, the EU-27 gained the most in new media, publishing and trading in antiques, but it has lost comparative advantage in the fields of video games, interior design, and arts and crafts. For 11 EU countries, data was also available in the form of trade balances, showing that these countries imported more creative industries goods and services than they exported. However, between 2000 and 2005 the balance improved due to a more rapid growth in exports. Looking at the character of goods and services traded in creative industries, an important share of royalties and licence fees can be observed: it accounts for $24 \%$ of both imports and exports in the 11 selected EU countries. This again points to the central role of intellectual property and copyright in creative industries on an international scale (cf. European Commission, 2010b).

Looking at Eurostat Business Survey data, it becomes obvious that the internal EU market is less important for creative industries. Only about $13 \%$ of all creative businesses engage in cross-border activities. The main barriers causing this relatively low share are difficulties in the identification of clients in other countries, the lack of international standards for services, and language and cultural barriers (European Commission, 2010b: 208).

This review of the literature dealing with the internationality of creative industries suggests that one can observe an increasing integration of creative industries into global markets. This is more driven by international trade than by international labour mobility. Several barriers cause the low degree of international labour mobility. First, production is rooted in national and local cultural contexts and linguistic systems. Additionally, institutional settings differ between countries within the supposedly free EU labour market. These differences translate into difficulties with the transferability of social security rights as well as the recognition of foreign educational certificates. Given the creative industries' reliance on highly-skilled workers, the non-transferability of certificates between countries is a large problem. Furthermore, remembering the often high risk that creative knowledge workers have to bear in their poorly regulated labour market, the non-transferability of social security between countries represents another obstacle to international mobility.

\subsection{Synthesis: Creative Industries}

Creative industries have emerged as a new field of economic activity since the beginning of deindustrialization in the 1970s. The emergence of these economic activities 
is also linked to the broader individualization process in society, the general restructuring of the economy as a whole (e.g. outsourcing processes) and the acceleration of product life cycles, as well as the global integration of markets and the related cultural complexities (Lange, 2007). This economic sector responds to the need for a rapid development of new and individualised products and services in more flexible ways. Additionally these creative products and services have to be sold in more emotional ways by not only selling the product but a complete lifestyle. Therefore, a higher input of knowledge and creativity is necessary (Musterd et al., 2007).

Creative knowledge work is characterised by a high share of non-manual tasks and 'brain work'. It consists of thinking about new solutions for current problems; thus it entails much conceptual and reflexive work. It is less repetitive and can rarely be standardised or automatised. As problem solving and innovation is a rather complex task that often needs highly specialised experts for the solution of a single piece of a larger problem, creative knowledge work is organised in continuously changing project ecologies with a changing composition of experts (Lange, 2007).

This means that the market is structured in a large share of very small and specialised economic production units (freelancers, micro and small companies) and a small share of large multinational companies controlling distribution (Henninger \& Gottschall, 2007; Hesmondhalgh \& Baker, 2008; Gill \& Pratt, 2008). This structure in the creative industries leads to power asymmetries (with a few large multinational companies having power over price mechanisms) which then have consequences for individual workers.

As such, creative knowledge workers participate in a very insecure labour market sector, which provides mostly short-term and project-based employment. This insecurity is evaluated as precarity by some scholars (Neilson \& Rossiter, 2005). Despite having comparably high educational attainment, creative knowledge workers face employment and income instability, a comparatively high workload and less leisure time (Brown et al., 2010). On the other hand, this flexible market organization is also understood as reflecting the individual freedom of creative knowledge workers (Friebe \& Lobo, 2006). They are often satisfied with their work-life balance and indicate being happy with their employment situation because they can actuate themselves, define work tasks autonomously and feel free to accept or decline jobs according to personal interest. This image of the creative knowledge worker can be understood as a traditional trade-off between security and freedom (Brown et al., 2010). Creative knowledge workers are more self-reliant and bear more individual autonomy than other sectors' workers. This leads to a higher identification with their professional life and a voluntary and playful blurring between leisure and work andbetween the private and the public (accentuation of the positive side of creative knowledge work - 'freedom'; $\mathrm{cf}$. Friebe \& Lobo, 2006). However, they also face a stronger exposure to the risk of selfexploitation, working a lot for a small income due to being too idealistic about their work (accentuation of the negative side of creative knowledge work - 'insecurity'; e.g. in Bröckling, 2007). 
Studying the lifeworlds and spatial attachments of creative knowledge workers is particularly interesting for several reasons. Due to their increased insecurity of employment and income, we can assume that they are partly forced into multilocal lifestyles more often than workers in traditional industries. Being mobile and finding work in different places is a chance for income increase and risk diversification. Furthermore, being involved in different places has a stimulating effect on creative knowledge workers and this could be considered an input to the production of knowledge and ideas. Combining different local creative networks might mulitply a worker's access to cultural knowledge and resources. Being confronted with the unknown or even the foreign could provide a stimulus for transfer and creativity. Moving around might help to improve one's individual expertise and labour value. Finally, creative knowledge work deals with symbolic values; therefore, it has a strong relation to national cultural backgrounds and language. It is thus of utmost interest to find out how transnationalism can be used as an asset for production in creative knowledge industries. So far, we have only learned that transnationalism could be a challenge, given the strong rootedness of creative knowledge work in national cultural contexts.

To conclude, I think that the mobile creative knowledge workers are an interesting group to study in detail. So far, no sufficient empirical results exist on the issue of multilocality and cross-border mobility in creative industries. The field has yet to be explored. In particular, as individualised and autonomous creative knowledge workers are self-sufficient, I propose that they must also organise their mobility to a large degree on an individual base. In doing so, they differ from the often studied groups of highly-skilled transnational expatriates who operate in the frame of multinational corporations (Pethe, 2007; Favell, 2008). Pethe et al. (2010: 186) consider expatriates as those type of migrants 'who have little choice over the country they are seconded to.' Their employing companies 'allocate their employees due to their needs' (Pethe et al., 2010: 164). For these expatriates, it is their company that organises their mobility. The company says where they must immigrate and for how long. The company organises a relocation service, the schooling for the children in the foreign destination, the socialisation for the accompanying partners, etc. However, creative knowledge workers have to construct their careers and employment paths autonomously. In most cases a large transnational corporation is not at hand (except for the few large gatekeeper companies in the distribution activities). Creative knowledge workers must organise the relocation on their own and are thus forced to deal with all the everyday life problems in the unknown and foreign places.

Mobile creative knowledge workers will then supposedly also differ from the managing elites as described e.g. by Nowicka (2005). Nowicka studied the lifeworlds of high-level employees of the United Nations. Similar to multinational corporations' expatriates, these administrative elites are also pampered by their organization. Having quasi-diplomatic immunity, they can move freely between countries without confronting national bureaucracy and immigration law. They take part in the UN's own social security schemes, therefore facing no problems of transferability between 
countries, and they are provided with relocation services, too. Thus, their contact and interaction with national and local culture remains relatively superficial. These people rather circulate within their own cosmopolitanism (Nowicka, 2005). By contrast, creative knowledge workers, I would suggest, are simultaneously forced to and volunteer to make contact with the local population and local specificity. They might seek contact to the local everyday life as this represents a creative stimulus. Based on the literature, I would assume that mobile creative knowledge workers have a professional curiosity in foreign culture. Foreign culture in combination with their own cultural background might lead to completely new and hybrid creative products.

Given the currently strong focus on expatriate elites in migration studies, Pethe (2007: 228f.) resumes: 'The diversity of different groups of migrants and the variety of processes, which influence the migration are only partly mapped out and not systematically compared. A new research agenda should take this into account. For example, little is known about highly skilled professionals who searched for new positions abroad independently.' I will undertake an attempt to study such highly skilled and self-dependent professionals in the form of mobile creative knowledge workers. Yet, before looking at empirical data, we should take a more detailed look at the interrelation between people's 'roots' and 'routes' in the following two chapters. 